Article

\title{
Ku- and Ka-Band Ocean Surface Radar Backscatter Model Functions at Low-Incidence Angles Using Full-Swath GPM DPR Data
}

\author{
Alamgir Hossan * (D) and William Linwood Jones
}

check for

updates

Citation: Hossan, A.; Jones, W.L. Kuand Ka-Band Ocean Surface Radar Backscatter Model Functions at

Low-Incidence Angles Using

Full-Swath GPM DPR Data. Remote Sens. 2021, 13, 1569. https://doi.org/ $10.3390 /$ rs13081569

Academic Editors: Bryan Stiles,

Svetla Hristova-Veleva,

Lucrezia Ricciardulli, Larry O'Neill, Zorana Jelenak and Joe Sapp

Received: 5 March 2021

Accepted: 15 April 2021

Published: 18 April 2021

Publisher's Note: MDPI stays neutral with regard to jurisdictional claims in published maps and institutional affiliations.

Copyright: (c) 2021 by the authors. Licensee MDPI, Basel, Switzerland. This article is an open access article distributed under the terms and conditions of the Creative Commons Attribution (CC BY) license (https:// creativecommons.org/licenses/by/ $4.0 /)$.
Central Florida Remote Sensing Laboratory, Department of Electrical and Computer Engineering, University of Central Florida, Orlando, FL 32816-2362, USA; Ljones@ucf.edu

* Correspondence: ah@knights.ucf.edu; Tel.: +1-321-947-9935

Abstract: This paper presents the results of the first characterization of coincident $\mathrm{Ku}$ - and $\mathrm{Ka}$ band ocean surface normalized radar cross section measurements at earth incidence angles $0^{\circ}-18^{\circ}$ using one year of wide swath Global Precipitation Measurement (GPM) mission dual frequency precipitation radar (DPR) data. Empirical geophysical model functions were derived for both bands, isotropic and directorial sensitivity were assessed, and finally, sea surface temperature (SST) dependence of radar backscatter, at both bands, were investigated. The Ka-band exhibited higher vector wind sensitivity for a low-to-moderate wind speeds regime, and the SST effects were also observed to be substantially larger at Ka-band than at Ku-band.

Keywords: ocean normalized radar cross section; near-nadir; GPM-core observatory; DPR; sea surface roughness scattering; space borne radar; Ku-band radar; Ka-band radar

\section{Introduction}

A robust empirical model of the relationship between ocean surface normalized radar cross section (known as $\sigma^{0}$ ) and associated geophysical parameters (especially the ocean wind speed and direction and sea surface temperature) is essential for the development of an accurate ocean vector wind (OVW) retrieval algorithm. Moreover, knowledge of ocean $\sigma^{0}$ is also crucial for on-orbit radar calibration of active remote sensors and for correcting atmospheric path attenuation in satellite cloud and rain profiling radars [1]. While the literature for ocean $\sigma^{0}$ is extensive, the majority of studies concern either radar scatterometers at moderate earth incidence angles (EIA) or nadir-viewing radar altimeters that operate at the $\mathrm{Ku}$ - or C-band frequencies.

On the other hand, the satellite Ku-band Precipitation Radars (PR) onboard Tropical Rainfall Measuring Mission (TRMM) [2] and the Ku/Ka-band Dual-frequency Precipitation Radar (DPR) on the follow-on Global Precipitation Mission (GPM) [3,4] also measure ocean backscatter from space. These radars view the surface at near-nadir EIA, with cross track scans within $\pm 18^{\circ}$; this scenario offers a unique scientific opportunity to investigate air/sea interaction processes as a function of wind and wave parameters from non-sun synchronous, low-earth orbiting satellites. Notable among near-nadir ocean backscatter studies were: Freilich and Vanhoff (2003) [5], who established an empirical relation between ocean surface $\sigma^{0}$ and wind speed for EIA $0^{\circ}-18^{\circ}$ using TRMM Ku PR measurements; Jones et al. (2002) [6] and Souisvarn et al. (2003) [7], who were the first to characterize the TRMM $\mathrm{Ku}$ PR $\sigma^{0}$ wind direction anisotropy for EIA $12^{\circ}-18^{\circ}$ over wind speeds of $3-9 \mathrm{~m} / \mathrm{s}$; Li et al. (2004) [8], who first demonstrated the wind speed (WS) retrieval from TRMM PR; and finally, Tran and Chapron (2006) [9], who first reported the directional anisotropy and sea state dependency of nadir $\sigma^{0}$ measurements by Ku- and C-band satellite altimeters and also near-nadir measurements from TRMM PR [10]. More recently, an investigation by Chu et al. (2012a) [11] provided a comprehensive analysis of near nadir $\sigma^{0}$ as a function of combined 
wind vector and wave parameters (including wave height and steepness) by using a large set of collocated TRMM PR and in situ data. Additionally, Chu et al. (2012b) [12] discussed the unique behavior the $\mathrm{Ku}$-band $\sigma^{0}$ at low incidence angles by analyzing its upwind-downwind asymmetry and upwind-crosswind directional modulations.

Prior to 2014, the ocean $\sigma^{0}$ at Ka-band was based on airborne experiments. Although these radar backscatter measurements provided valuable insights that indicated a similar behavior of Ka-band $\sigma^{0}$ to that at $\mathrm{Ku}$-band, results of various studies were inconsistent with each other [13]. In February 2014, the GPM satellite was launched, with the dual-frequency precipitation radar that provided the first space-based measurements of global ocean radar backscatter at low incidence angles at both $\mathrm{Ku}$ - and Ka-bands [14]. Recent studies analyzed these simultaneous GPM DPR $\sigma^{0}$ measurements $[15,16]$; however, results for Ka-band were limited to EIA of $\pm 9^{\circ}$ (corresponding to $\sim 125 \mathrm{~km}$ at the center of collocated Ku swath). Fortunately, on May 21, 2018, the Ka-band was reconfigured to provide fully collocated measurements with $\mathrm{Ku}$ PR over entire $\sim 250 \mathrm{~km}$ swath that corresponds to EIA range of $\pm 18^{\circ}[17]$.

In addition, Wang et al. (2017) [18] performed a comprehensive investigation of sea surface temperature (SST) effects on ocean surface $\sigma^{0}$ at the corresponding EIAs and polarizations for $\mathrm{C}$ - and $\mathrm{Ku}$-band scatterometers. Although negligible at $\mathrm{C}$ band, they concluded that SST effects were significant for $\mathrm{Ku}$ band and should be included in the ocean surface $\sigma^{0}$ geophysical model function (GMF). Based upon their findings, we performed a similar analysis of GPM DPR backscatter measurements at low incidence angles, and results are given herein that document of the effects of SST on Ka-band ocean radar backscatter.

Therefore, this paper presents the first comparative results from the full-swath, collocated, GPM DPR measurements, and separate (Ku- and Ka-band) GMFs are described for horizontal-polarization, which characterize the clear-sky, ocean surface $\sigma^{0}$ as a function of EIA and environmental parameters-namely, ocean surface wind speed (WS), wind direction (WD), and SST. The paper is organized as follows: instruments and data are described in Section 2. In Section 3, the WS, relative WD, and SST dependency of $\sigma^{0}$ and model description are provided. Comparative results at $\mathrm{Ku}$ and $\mathrm{Ka}$ band are also given in the same section, which is followed by the discussion in Section 4 . Section 5 concludes the paper by giving a summary.

\section{Materials and Methods}

The Global Precipitation Mission satellite was launched on 27 February, 2014 into a $65^{\circ}$ inclination, $407 \mathrm{~km}$ altitude, non-sun-synchronous orbit. This is a joint Earth Observation Science mission by the National Aeronautics and Space Administration (NASA) and the Japan Aerospace Exploration Agency (JAXA), which extends the TRMM time series [2,19] and enhances the measurement of global precipitation $[3,14]$. The satellite carries two microwave remote sensors, namely, a passive GPM microwave imager (GMI) and a dualfrequency precipitation radar (DPR).

\subsection{GPM Dual-Frequency Precipitation Radar (DPR)}

A Ku-band (13.6 GHz, H pol) precipitation radar (KuPR) and a new Ka-band (35.5 GHz, $\mathrm{H}$ pol) precipitation radar (KaPR) form the dual-frequency precipitation radar (DPR) onboard the GPM core observatory as shown in Figure 1. The GPM KuPR (and TRMM PR) have an identical geometry that uses an electronically scanned phased array to scan the surface perpendicularly to the flight direction at 49 beam positions over an EIA $\pm 18^{\circ}$. Contiguous beams are separated by about $0.75^{\circ}$ in earth incidence angle, resulting a spatial footprint of about $5 \mathrm{~km}$ in diameter that produces a continuous $245 \mathrm{~km}$ measurement swath. The Ka PR also has 49 cross-track beams with the same beam width as Ku PR, but initially, only 25 of the Ka-band beams with the same range resolution as the KuPR (250 m) were overlapped with the central 25 beams of KuPR resulting in a common swath of $125 \mathrm{~km}$, as shown in Figure 2a. These $25 \mathrm{Ka}$-band beams are called "matched scan (KaMS)", and the other 24 beams which have a different range resolution $(500 \mathrm{~m})$ and are called "high 
sensitivity scan (KaHS)" because of their superior noise performance, were interleaved with the KaMS beams as shown in Figure 2a. However, on 21 May 2018, the Ka-band radar was reconfigured as shown in Figure 2b, to provide coincident measurements with KuPR over a full $245 \mathrm{~km}$ common swath [17]. This new configuration allows a comparison of radar backscatter characteristics at both frequencies for low EIA (nadir $\pm 18^{\circ}$ ).

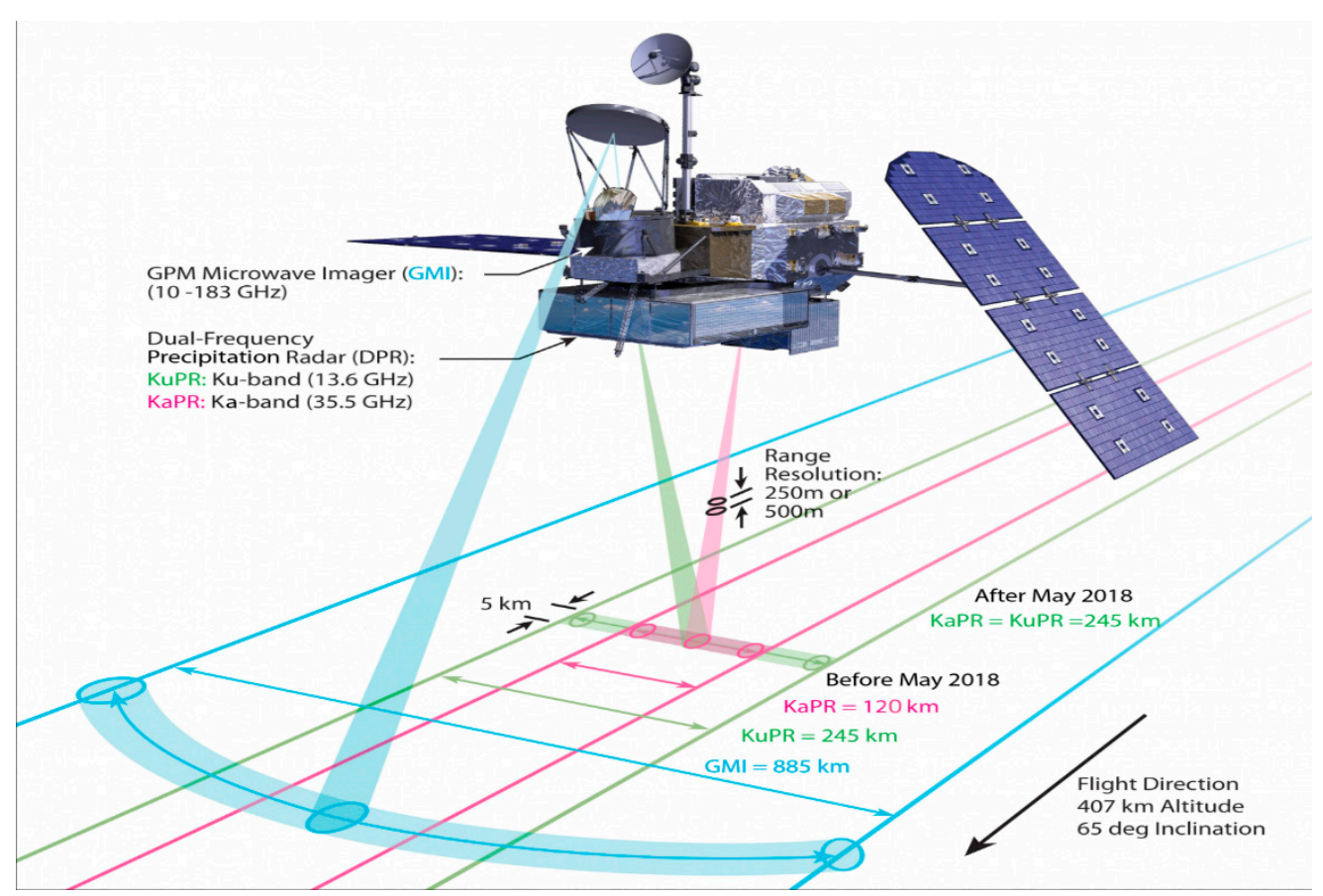

Figure 1. Global Precipitation Measurement (GPM) core observatory with the GPM Microwave Imager (GMI) and dual frequency precipitation radar (DPR) sensors and their swath coverage (Courtesy: NASA).

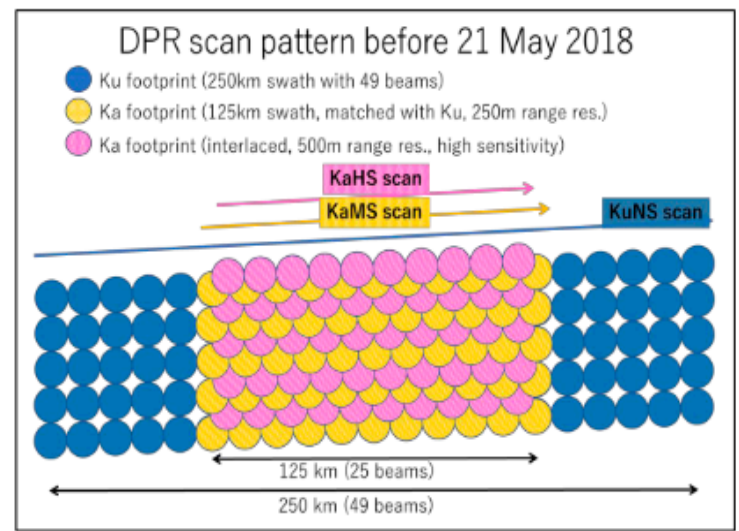

(a)

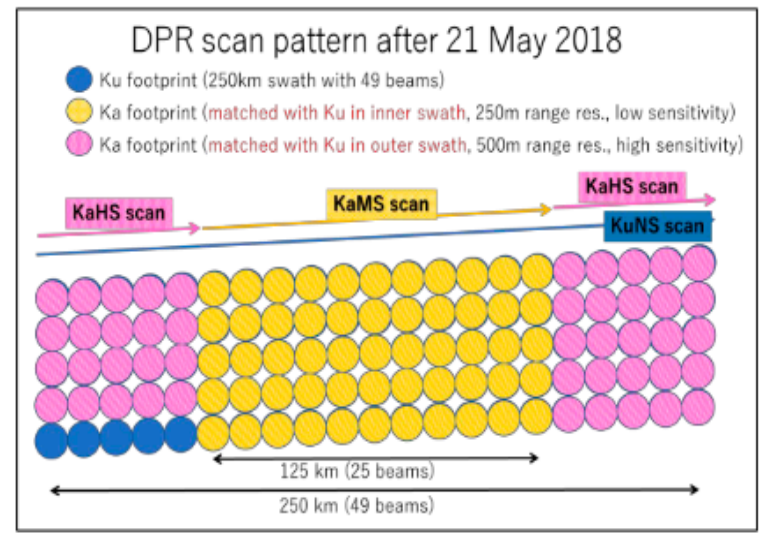

(b)

Figure 2. Scan pattern of GPM DPR: (a) before 21 May, 2018 and (b) after 21 May, 2018. Blue circles indicate Ku-band precipitation radar (KuPR) footprints, while yellow and pink circles represent a matched (KaMS), and highly sensitive (KaHS) swath of Ka, respectively [17].

\subsection{GPM Microwave Imager (GMI)}

The GPM Microwave Imager (GMI) is a well-calibrated, multi-channel, conical scanning total power microwave radiometer with a $931 \mathrm{~km}$ wide swath. It has 13 channels with frequency ranging from 10.65 to $183.31 \mathrm{GHz}$, each of which is dual-polarized (except the 23.8 GHz channel which has only V pol). A $245 \mathrm{~km}$ DPR swath lies at the center of the $931 \mathrm{~km}$ GMI swath, as shown in Figure 1, which simplifies the collocation between these 
two sensor measurements. Since the focus of this paper is DPR, a detailed discussion of GMI is beyond the scope of this paper, but it can be found in [20]. We used GMI wind speed (WS), and sea surface temperature (SST) retrieved by the Remote Sensing System [21]. They used intercalibrated GMI brightness temperatures $(\mathrm{Tb})$ to produce ocean measurement products including WS and SST. Because the RSS GMI products are simultaneous with DPR measurements, they are expected to be more appropriate than the wind products extracted from a numerical weather forecast model.

\subsection{Collocation and Quality Control}

One year (2019) of Ku PR level 2 standard (2A.GPM.Ku.V8-20180723. V06A) and Ka PR experimental (2A.GPM.KaX.V8-20200326.V06X) products from the NASA GPM research data archive (https: / / arthurhou.pps.eosdis.nasa.gov, accessed on 15 April 2021) were used in this study. In addition to atmospheric attenuation corrected ocean surface $\sigma^{0}$, the DPR product also contains navigation, sensor geometry, geolocation, and quality flags. PR rain, surface type and data quality flags were used to filter the radar backscatter to ensure rain-free ocean $\sigma^{0}$ measurements, which were then smoothed (using a triangular moving average filter) to remove quantization noise caused by analog/digital conversion. Finally, the filtered ocean $\sigma^{0}$ measurements were collocated with pertinent environmental parameters from two sources to provide a "match-up" dataset.

The first source of environmental parameters (WS and SST) were geophysical retrievals from coincident passive microwave GMI brightness temperatures (Tbs). These data were provided by the Remote Sensing Systems (RSS) archive (http:/ / www.remss.com/missions / gmi/, accessed on 15 April 2021) [21] in the form of daily $0.25^{\circ}$ earth gridded maps that were separated into ascending and descending orbit segments. For the $10 \mathrm{~m}$ wind speed, we used the product that was derived from low frequency channels $(10.7,18.7,23.8$, and 36.5 GHz).

The second source of environmental parameters was the European Centre for MediumRange Weather Forecasts (ECMWF) global atmospheric reanalysis (ERA-5) [22]. Hourly 10-meter wind vector and SST products with $31 \mathrm{~km}$ grid spacing are available in ERA-5, which were re-gridded in $0.25^{\circ}$ to match with GMI products.

Finally, the match-up dataset was completed by gridding the GPM DPR data $(\mathrm{Ku}$ and Ka) into $0.25^{\circ} \times 0.25^{\circ}$ boxes, with associated GMI derived WS and SST and ERA-5 WD. All $\sigma^{0}$ measurements in a box were averaged (in linear units) and boxes with a high standard deviation were discarded, and RSS data quality flags were also used to exclude any rain, sea-ice, and land contaminated data from the match-up dataset. Since DPR and GMI obtain near-simultaneous observations over a common ocean surface sub swath, the one-year time series resulted in millions of co-located, clear-sky global ocean measurements over a wide variety of environmental conditions. This provides a unique $\mathrm{Ku} / \mathrm{Ka} \sigma^{0}$ match-up dataset that is reported for the first time in this paper. Results were produced using two environmental sets, one using GMI WS and SST with ERA-5 WD, and the other using all ERA-5 products (WS, WD, and SST). The differences were insignificant, except some mean biases (dc-offsets) between the two results. Therefore, the results with the former combination are presented in this paper.

\section{Geophysical Model Function for the Ocean Ku and Ka-Band PR Backscatter}

The microwave ocean surface radar backscatter $\left(\sigma^{0}\right)$ at the GPM DPR incidence angle range $\left(0^{\circ}\right.$ to $\left.18^{\circ}\right)$ are dominated by quasi-specular scattering process, but towards the outer swath, the resonant (Bragg) scattering process also becomes significant [5]. For both regimes, the $\sigma^{0}$ is directly related to the ocean surface wind vector (OVW), SST, and integral wave parameters $[9-12,15,23,24]$. The backscatter can be empirically modeled as a 2 nd order Fourier series (higher order terms are negligible),

$$
\sigma_{d B}^{\circ}(f, p)=A_{0}+A_{1} \cos (\chi)+A_{2} \cos (2 \chi)+B_{1} \sin (\chi)+B_{2} \sin (2 \chi)
$$


where $\sigma^{\circ}{ }_{d B}(f, p)$ is the sea surface normalized radar cross section at a frequency $(f)$ and polarization $(p)$ in $\mathrm{dB}$ unit. The model coefficients $A_{0}, A_{1}, A_{2}, B_{1}$, and $B_{2}$ are wind speed, EIA and sea-state dependent, and $\chi$ denotes the wind direction relative to the radar azimuth look defined as $\chi=\varphi_{\text {wind }}-\varphi_{\text {radar }}$, where $\varphi_{\text {wind }}$ is the meteorological wind direction (i.e., the direction where the wind is coming from), and $\varphi_{\text {radar }}$ for DPR, is cross-track azimuth look (flight direction $\pm 90^{\circ}$ ), both referring to the North. Accordingly, $\chi=0$ denotes the upwind specifying that the wind is blowing toward the radar look direction. Since both, $\mathrm{Ku}$ and Ka PR onboard GPM operate at only horizontal polarization, all references to polarization are omitted in this paper.

Historically, the radar ocean backscatter GMF has been modeled as a cosine Fourier series [25,26], but our initial analysis used both sine and cosine terms in Equation (1). However, after a comprehensive investigation, it was concluded that the sine terms were not statistically significant, and as a result, they were neglected. Figure 3 illustrates a typical comparison of the GMF, with and without the sine terms, for an EIA $=16^{\circ}$ and WS of 16 $\mathrm{m} / \mathrm{s}$. The circle symbols are the residual $\left.\left[<\sigma^{0}\right\rangle-A_{0}\right]$ of empirical bin average $\left\langle\sigma^{0}\right\rangle$, and the red solid line is the full model (Equation (1), sines and cosines) and the blue solid line is the cosine alone GMF. As shown, the contribution of the odd terms is negligible and the $\sigma^{0}$ azimuth anisotropy can be well approximated by only even terms.

$$
\sigma_{d B}^{\circ}(f, p)=A_{0}+A_{1} \cos (\chi)+A_{2} \cos (2 \chi)
$$

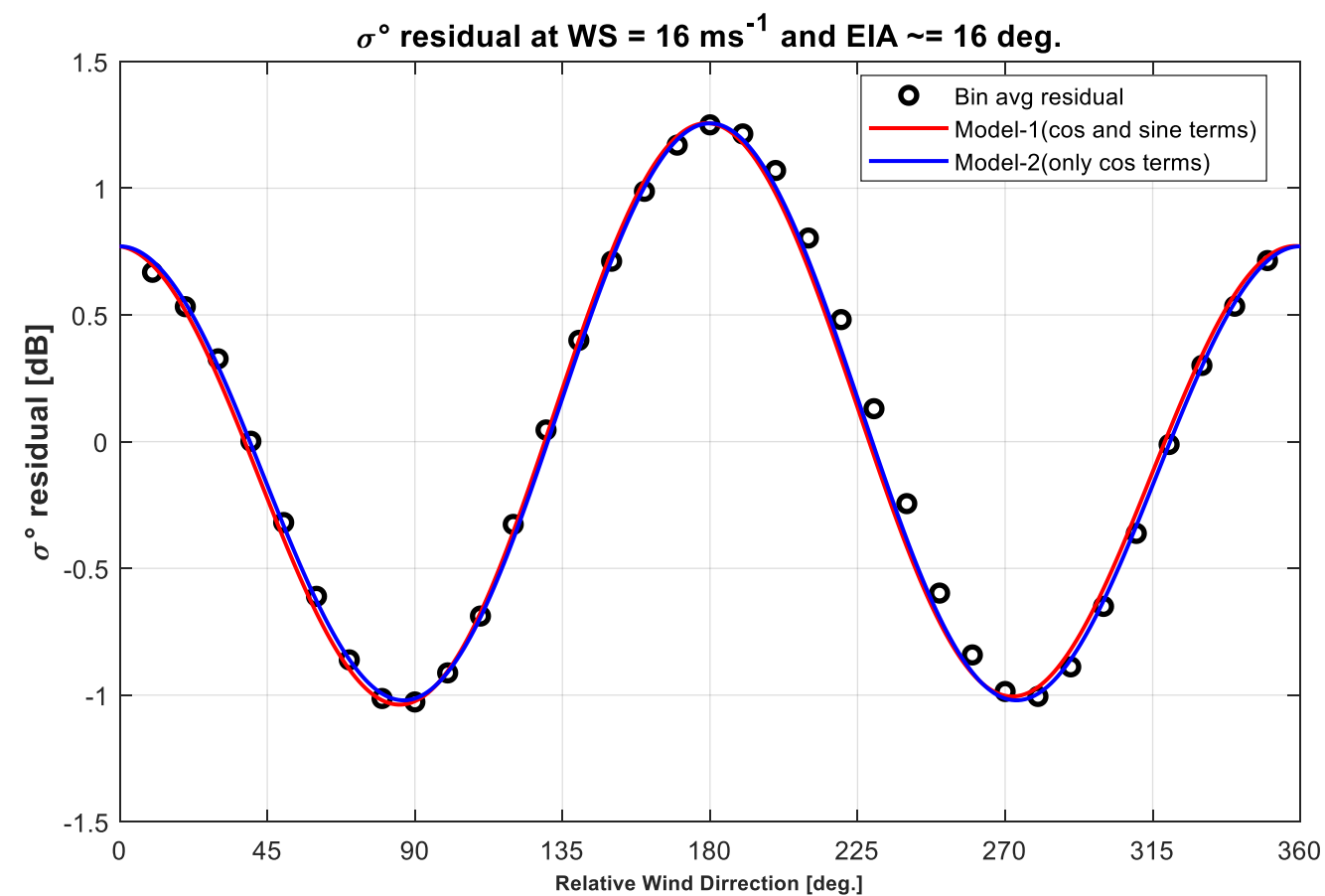

Figure 3. Effect of odd and even terms (in $\mathrm{dB}$ ) in the ocean $\sigma^{0}$ backscatter model at low earth incidence angles (EIAs).

It should be noted that Equation (2) is the same expression used to model the ocean backscatter at moderate EIAs $\left(20^{\circ}-70^{\circ}\right)$, but here, as will be depicted in the next section, the $A_{1}$ term is negative for EIA $<20^{\circ}$, which results in a reversal of upwind and downwind asymmetry, i.e., higher downwind backscatter than the upwind backscatter.

In this section, the dependence and sensitivity of $\mathrm{Ku}$ and $\mathrm{Ka}$ band $\sigma^{0}$ on EIA, and the ocean surface wind speed, and wind direction are analyzed. Fourier coefficients $A_{0}, A_{1}$ and $A_{2}$ are derived using $\sigma^{0}$ measurements for each angular beam (EIA) positions, and finally, these coefficients are modeled as a function of wind speed using polynomial fit of appropriate orders. Additionally, the SST dependence of $\mathrm{Ku}$ and Ka band $\sigma^{0}$ is discussed. Results of sea state dependence of $\sigma^{0}$ are not included in this paper; however, readers are encouraged to see $[9,10,12,15]$ for this. 


\subsection{Isotropic Ku and Ka-Band $\sigma^{0}$ Model Function at Low Incidence Angles}

The $A_{0}$ coefficient in Equation (1) is the azimuth independent (isotropic) $\sigma^{0}$ measurement that is directly related to the wind speed (WS) for a particular earth incidence angle (EIA). Thus, it can be modeled as,

$$
A_{0}=\sigma_{d B}^{\circ}(\mathrm{WS}, \text { EIA })
$$

In order to analyze, $A_{0}$, the normalized radar backscatter $\left(\sigma^{0}\right)$ measurements of the $\mathrm{Ku}$ and Ka-bands were sorted in $\pm 1 \mathrm{~ms}^{-1}$ wind speed bins for each of 49 EIA beams. A conservative $3 \sigma$ filter was applied to each bin to remove outliers (the $3 \sigma$ values were calculated in linear, not $\mathrm{dB}$, units), and any bin with less than 500 boxes was not included in the analysis. Next, using polynomial regression (in $\mathrm{dB}$ space), the bin average $\sigma^{0}$ for each of this EIA position were expanded as a third-order polynomial of log (WS). The use of $\log (\mathrm{WS})$ for $A_{0}$ reduces the order of the polynomial fit.

$$
A_{0}=a_{01} x^{3}+a_{02} x^{2}+a_{03} x+a_{04}
$$

where $\mathrm{x}=\log _{10}(\mathrm{WS})$, and the numerical values of these coefficients (in $\mathrm{dB}$ ) are given in the Table A1 in Appendix A for EIA $0^{\circ}$ to $18.1^{\circ}$ (Beams 1 to 25).

The dependence of $A_{0}$ on WS is illustrated in Figure 4 using a log-log plot, for eight PR beam positions that include EIAs nadir to $18.1^{\circ}$. The circle symbols represent the mean value of $\sigma^{0}$ measurements over all wind directions and the solid lines are their third-order polynomial fits, both in $\mathrm{dB}$. At the higher EIA beam positions, $\sigma^{0}$ monotonically increases with wind speed, whereas it monotonically decreases for lower EIAs near nadir. For the middle EIA beam positions, the $\sigma^{0}$ dependence is not monotonic because there are two different scattering mechanisms involved. Namely, the near nadir backscatter is dominated by quasi-specular scattering that decreases $\sigma^{0}$ with increased ocean roughness, but as EIA increases, Bragg scattering gradually becomes significant that increases $\sigma^{0}$ with WS. These $\mathrm{Ku}$ results are consistent with [5-12,15], except for a small calibration bias between TRMM PR and GPM KuPR.
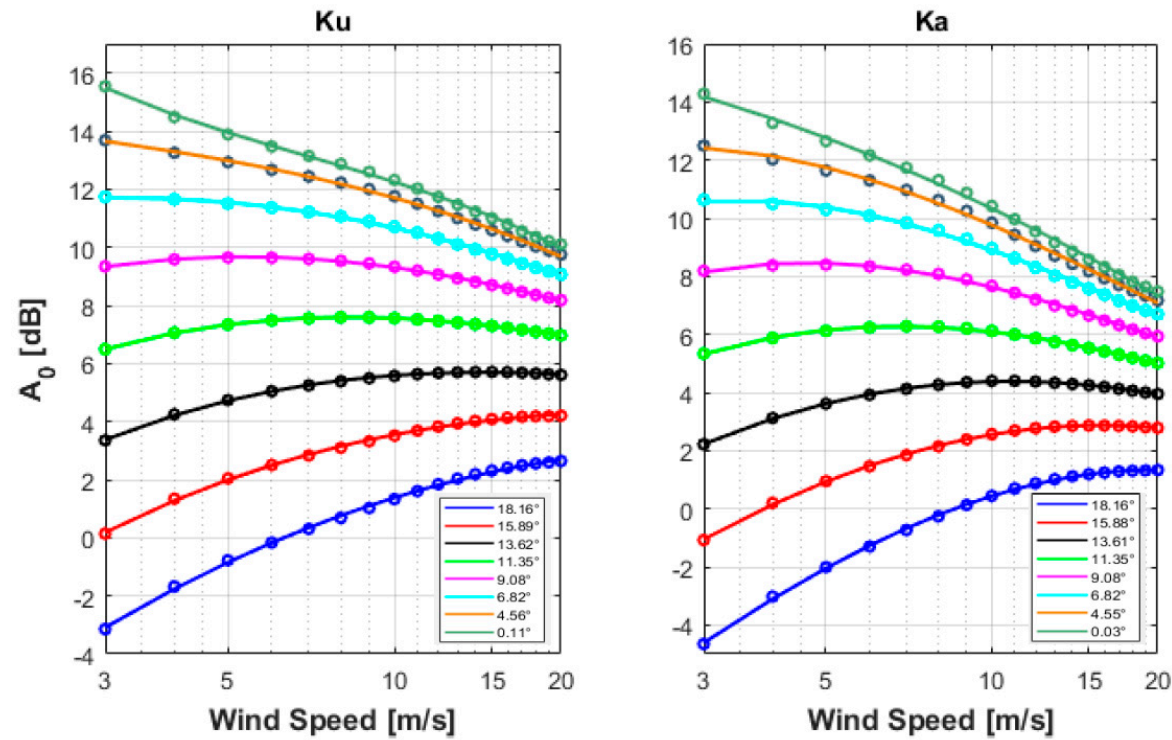

Figure 4. Isotropic $\sigma^{0}$ models $\left(A_{0}\right.$ coefficients in $\mathrm{dB}$ ) of KuPR (left) and Ka-band precipitation (KaPR) (right) as a function of wind speed $\left(3-20 \mathrm{~ms}^{-1}\right)$ at different earth incidence angles $\left(0^{\circ}-18.1^{\circ}\right)$. The symbols are mean values of binned $\sigma^{0}$ measurements while the solid lines represent their 3rd order regression fits.

While these results (Figure 4) are qualitatively similar for Ka PR, there are small differences between the $A_{0}$ GMFs (Equation (4)) for Ku and Ka bands, and these differences 
are also a function of wind speed and incidence angle, as shown in Figure 5, which plots the differences of mean backscatter values $\left(\Delta A_{0}\right)$ of $\mathrm{Ku}$ and Ka models as a function of WS for different EIA beam positions. For the lower EIA beams, the difference increases monotonically with WS, but for the higher EIA beams, the difference first decreases with WS for lower to moderate WS, then it increases with WS for higher WS. However, for higher EIA beam positions, the differences are smaller than at lower EIA beam positions, for instance, the difference is less than $1.5 \mathrm{~dB}$ at EIA $\sim 16^{\circ}$ for any WS between 3 and $20 \mathrm{~m} / \mathrm{s}$. Beside this, the WS sensitivity or $\sigma^{0}$ gradient, defined as $\left(\frac{\partial \sigma^{0}}{\partial W S}\right)$, is shown in Figure 6 as a function of WS for the same beam positions corresponding to Figure 4. The slope of increase or decrease declines with WS at both bands. For Ka band, it declines slightly more rapidly than at Ku band for low WS region, whereas for medium to higher WS, the slopes are a little higher at Ku band. Figure 7 shows the scatter diagram of $\mathrm{Ku}$ and Ka PR mean $\sigma^{0}$ for six fixed EIA beam positions. Symbols represent the mean $\sigma^{0}$ for different wind speed bins ( 1 to $20 \mathrm{~m} / \mathrm{s}$ at $\pm 1 \mathrm{~m} / \mathrm{s}$ steps). As shown, for the outer beam positions (higher EIA), Ku and Ka PR mean $\sigma^{0}$ are linearly correlated, except for higher WS, where $\sigma^{0}$ become flat and start to decrease with WS. The drop of $\sigma^{0}$ with increasing WS begins at relatively lower WS at the inner beam positions (lower EIA) as shown at the bottom panel of the same Figure. These correlations between $\mathrm{Ku}$ and Ka PR mean $\sigma^{0}$ could be a useful alternative way to determine one from another, especially for outer beam positions. For example, the missing Ka outer swath for the initial phase of GPM mission (up to 22 May 2018) could be estimated from corresponding Ku band measurements. For higher WS at lower EIA, this approach would be difficult and more prone to error. However, the model derived in this paper (Equation (4)) is reliably applicable for WS 3-20 m/s for all EIA beam positions. Another important implication of Figure 7 is the variation of dynamic range of wind-roughened $\sigma^{0}$ with EIA. This is shown in Figure 8, which compares the maximum wind-dependent variation of Ku band mean $\sigma^{0}$ with that at Ka band. As shown, although both have similar dynamic ranges for EIA $\sim 9^{\circ}$, Ka band mean $\sigma^{0}$ has higher dynamic range for EIA $<9^{\circ}$.

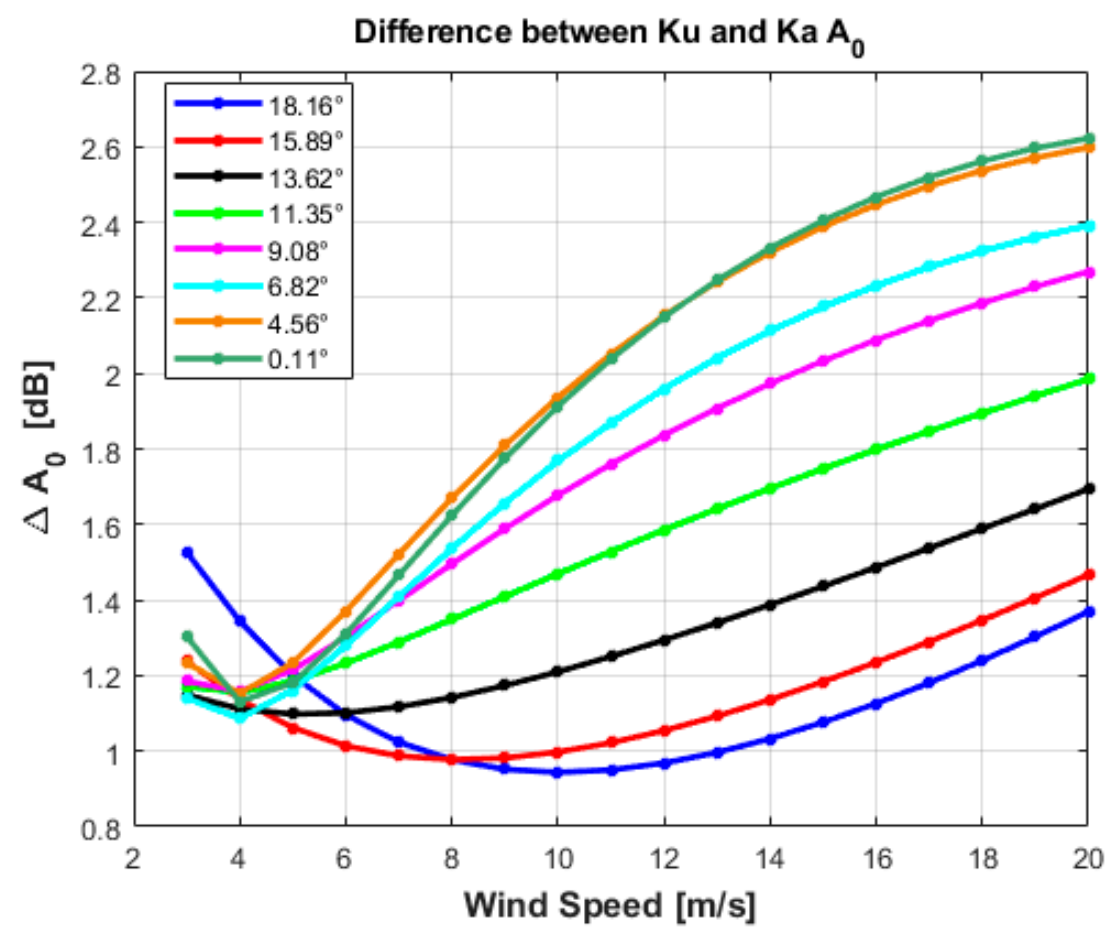

Figure 5. Difference between isotropic $\sigma^{0}$ models (in $\mathrm{dB}$ ) of $\mathrm{KuPR}$ and $\mathrm{KaPR}$ as a function of wind speed $\left(3-20 \mathrm{~ms}^{-1}\right)$ at different earth incidence angles $\left(0^{\circ}-18.1^{\circ}\right)$. 

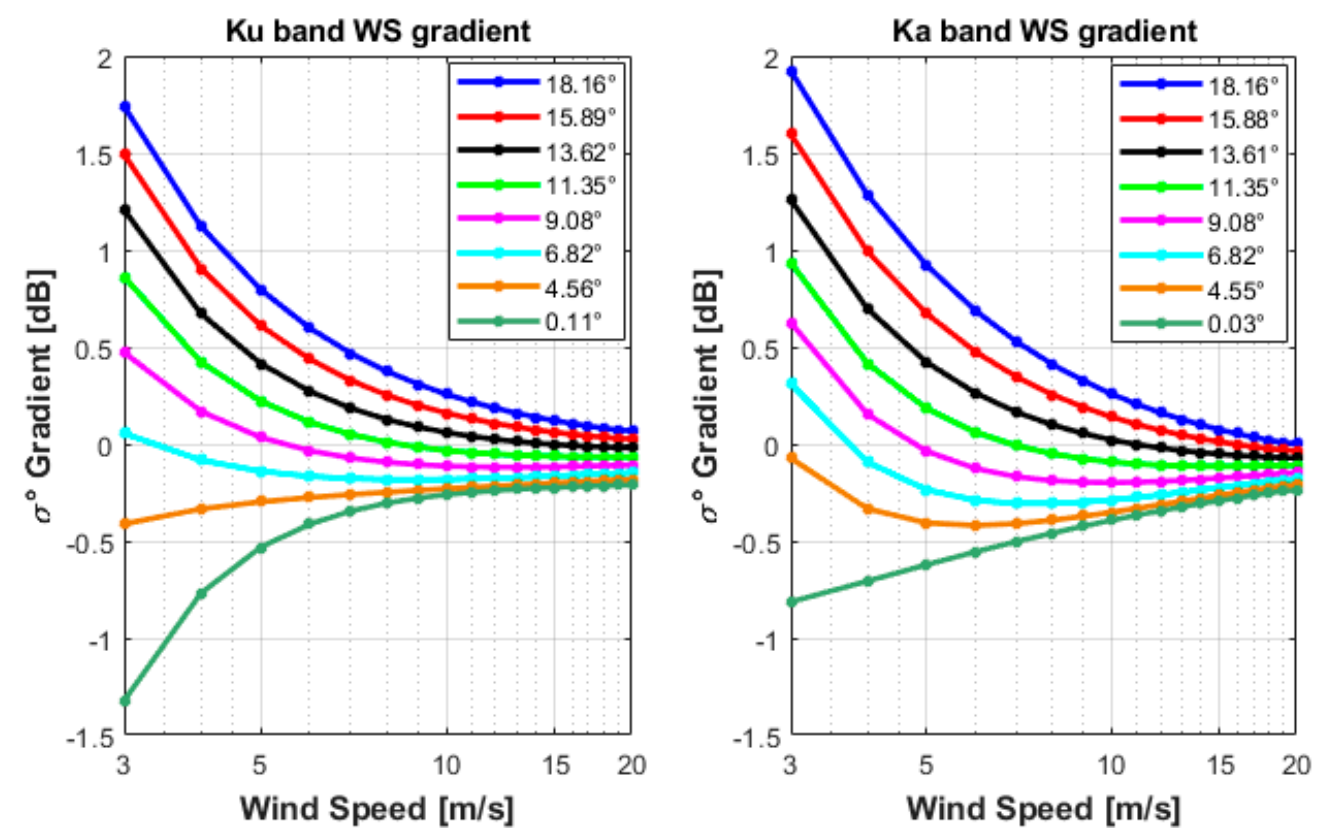

Figure 6. Gradient of KuPR (left) and KaPR (right) ocean surface normalized radar cross section $\left(\sigma^{0}\right)$ variation (in $\left.\mathrm{dB}\right)$ as a function of wind speed $\left(3-20 \mathrm{~ms}^{-1}\right)$ at different earth incidence angles $\left(0^{\circ}-18.1^{\circ}\right)$.
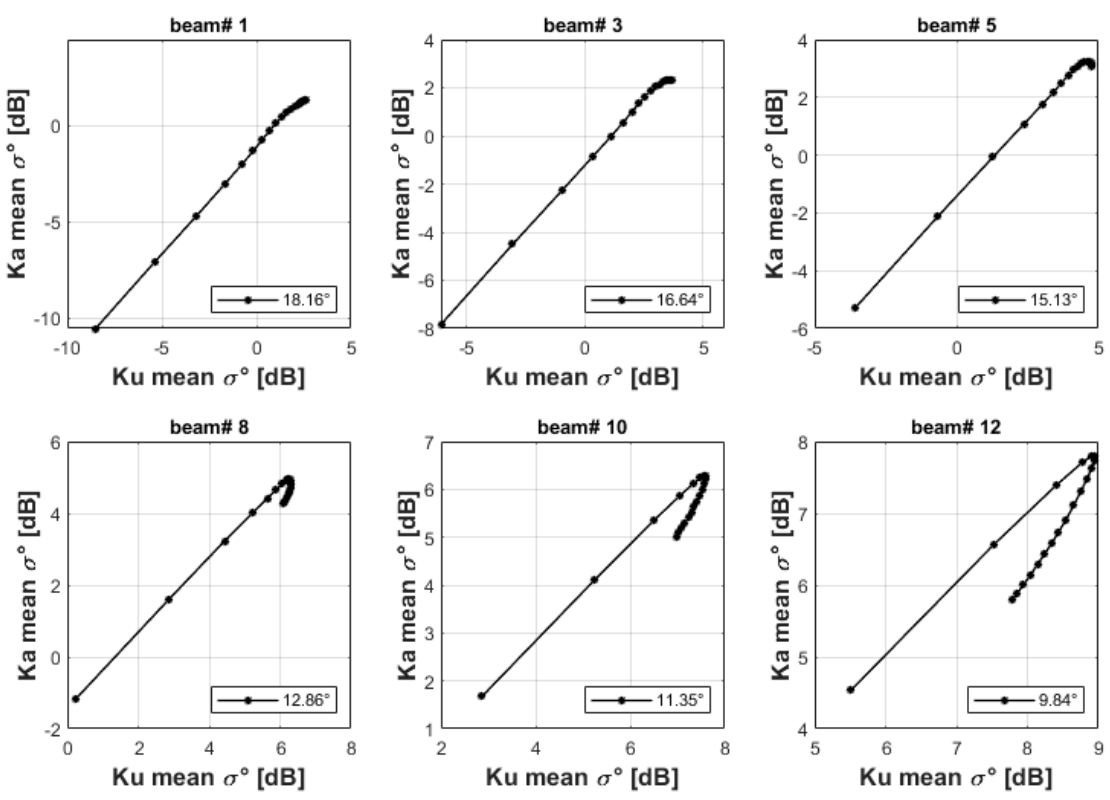

Figure 7. Scatter plot of KaPR mean $\sigma^{0}$ with KuPR mean $\sigma^{0}$ (in dB) for wind speed (WS) $=1-20 \mathrm{~ms}^{-1}$ at different angular beam positions.

Finally, the mean values of binned average $\sigma^{0}$ for $\mathrm{Ku}$ and $\mathrm{Ka}$ bands are shown in Figure 9 as a function of EIA for different wind speeds. The $\sigma^{0}$ monotonically decreases with increasing incidence angle from nadir to $18.2^{\circ}$. Additionally, the $\sigma^{0}$ decreases monotonically with wind speed at EIAs near nadir, but $\sigma^{0}$ increases monotonically with wind speed near EIA $18.2^{\circ}$, with a transition in the middle where $\sigma^{0}$ becomes relatively insensitive to WS (for WS $\geq 4 \mathrm{~ms}^{-1}$ ). For KuPR, this transition occurs over EIA $11^{\circ}-13^{\circ}$, whereas for $\mathrm{KaPR}$ it occurs over EIA $12^{\circ}-14^{\circ}$. Additionally, these transition regions vary with the relative azimuth look, for upwind/downwind/crosswind directions, as shown for KuPR in Figure 10 (these variations are proportionately similar at Ka-band which is not shown here). This EIA range of reduced $\sigma^{0}$ variability is useful for the radar inter-calibration between these kinds of instruments [5]. Therefore, based upon these results, we conclude 
that the two GMF's are similar and are applicable for a WS range of 3-20 $\mathrm{ms}^{-1}$ and for all EIA beam positions.

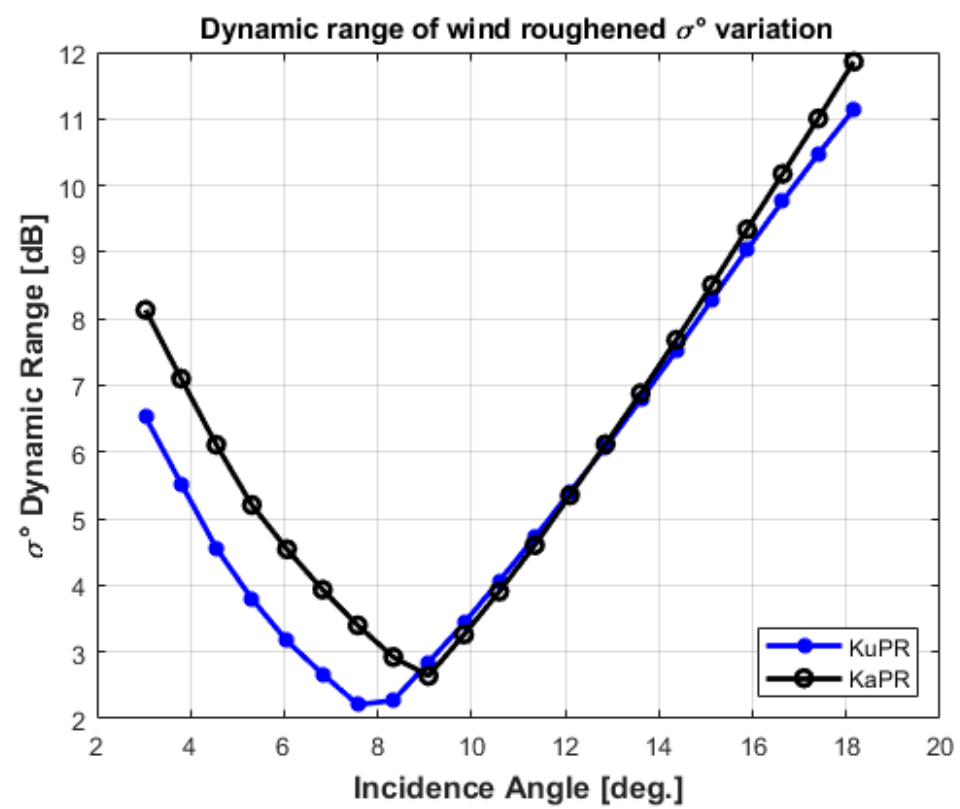

Figure 8. Dynamic range of wind roughened $\sigma^{0}$ (in dB) for $\mathrm{Ku}$ and $\mathrm{KaPR}$ for WS $=1-20 \mathrm{~ms}^{-1}$.
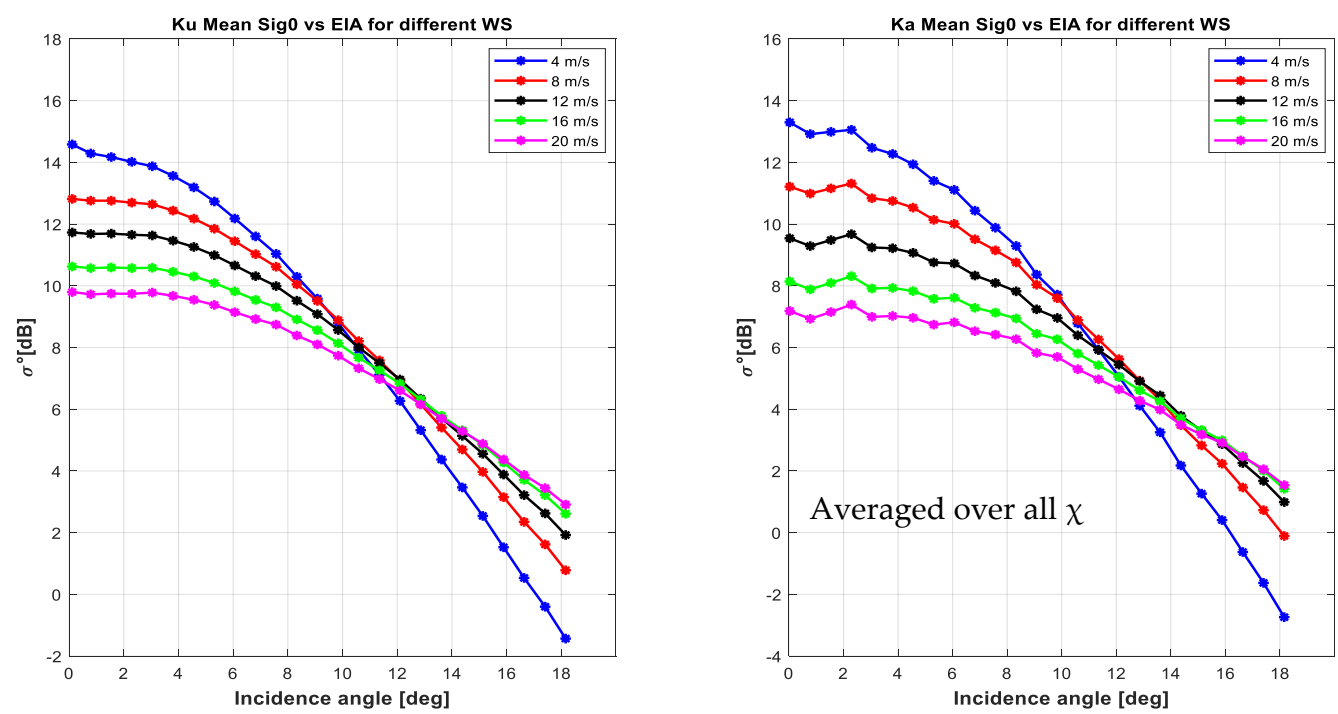

Figure 9. Mean value of binned $\sigma^{0}$ (in $\mathrm{dB}$ ) at KuPR (left) and $\mathrm{KaPR}$ (right) as a function of earth incidence angle $\theta$, for different wind speeds.

\section{2. $\sigma^{0}$ Azimuthal Anisotropy}

The directional anisotropy of ocean surface $\sigma^{0}$ is a function of WS, relative wind direction, and EIA. We can separate the directional signal of $\sigma^{0}$ (in $\mathrm{dB}$ ) by computing the residual of $\sigma^{0}$ as follows,

$$
\sigma^{0}-A_{0}=\sigma_{(\text {residual })}^{0}=A_{1} \cos (\chi)+A_{2} \cos (2 \chi)
$$

To analyze the directional anisotropy of both $\mathrm{KuPR}$ and $\mathrm{KaPR}$, in accordance with Equation (5), the $\sigma^{0}$ measurements in WS bins $( \pm 1 \mathrm{~m} / \mathrm{s})$ were further sorted into $10^{\circ}$ relative wind direction $(\chi)$ bins. Afterwards, the Fourier series approximation of Equation (2) was applied to the bin average of both $\mathrm{Ku}$ and $\mathrm{Ka} \mathrm{PR} \sigma^{0}$ (in dB space), to derive $A_{1}$ and $A_{2}$ 
coefficients for each WS and EIA bin position. Finally, $A_{1}$ and $A_{2}$ Fourier coefficients, thus derived, were modeled as a function of WS using third and seventh order polynomial regressions (in $\mathrm{dB}$ space), respectively. Unlike the case of $A_{0}$ in Equation (4), use of $\log$ (WS) for $A_{1}$ and $A_{1}$ does not reduce the order of the polynomials, thus WS measurements in linear units were used in these cases.

$$
A_{1}=a_{11} u^{3}+a_{12} u^{2}+a_{13} u+a_{14}
$$

and,

$$
A_{2}=a_{21} u^{7}+a_{22} u^{6}+a_{23} u^{5}+a_{24} u^{4}+a_{25} u^{3}+a_{26} u^{2}+a_{27} u+a_{28}
$$

where $u=W S$, and the values of the polynomial coefficients $a_{11}$ through $a_{14}$ and $a_{21}$ through $a_{28}$ (in $\mathrm{dB}$ ) are given in the Table A2, Table A3, and Table A4 in Appendix A for EIA $0^{\circ}$ to $18.1^{\circ}$ (Beams 1 to 25$)$.
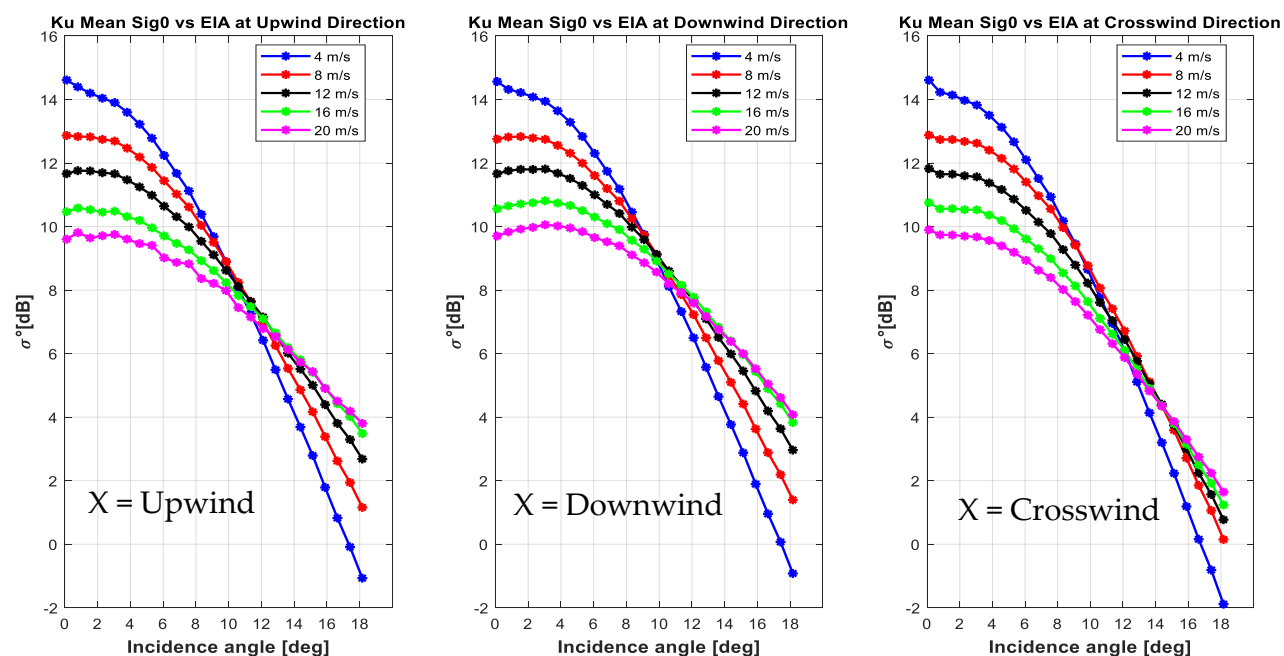

Figure 10. Mean value of binned $\sigma^{0}$ (in $\mathrm{dB}$ ) at $\mathrm{KuPR}$ as a function of earth incidence angle $\theta$, for different relative wind directions: upwind (leftmost), downwind (middle), and crosswind (rightmost).

The $A_{1}$ and $A_{2}$ coefficients, for the corresponding EIA beam positions, are shown as a function of WS in Figures 11 and 12, respectively. Symbols in both Figures represent the Fourier coefficients found from Equation (2), and the solid lines represent the corresponding polynomial fits (Equations (6) and (7)). For both bands, $A_{1}$ is negative, and the magnitude becomes more negative with increasing WS. Additionally, for the same EIA, the magnitude of the $\mathrm{Ka}$ band $A_{1}$ is slightly more negative, and the doubling of this coefficient is the measure of upwind-down wind asymmetry. For the $A_{2}$ coefficient, both bands have similar patterns, which decrease with increasing WS and reach a minimum (at $\sim 6 \mathrm{~m} / \mathrm{s}(\mathrm{Ku})$ and $\sim 5 \mathrm{~m} / \mathrm{s}(\mathrm{Ka})$ ). Afterwards, the magnitude of $A_{2}$ rapidly increases with WS until it approximately saturates at WS $\sim=14 \mathrm{~m} / \mathrm{s}$ for $\mathrm{Ku}$ band and $\mathrm{WS} \sim=12 \mathrm{~m} / \mathrm{s}$ for Ka band. The $A_{2}$ coefficient is a measure of upwind-crosswind asymmetry or total directional anisotropy, and it increases with EIA.

The residual (anomaly) of the KuPR $\sigma^{0}$ is presented in Figure 13 as a function of relative wind direction for selected EIAs and WS. The symbols are the residual of the measured bin average, and the solid lines are the corresponding model (Equation (5)). As shown, the bi-harmonic directional signal increases with both WS and EIA, and the model is in excellent agreement with the empirical measurements for all cases, except for the $6.8^{\circ}$ EIA (and less), which is slightly degraded for relative WD: $270^{\circ}-360^{\circ}$, especially for lower WS cases. The corresponding results for KaPR are presented in Figure 14, but for these cases the quality of the model fit is somewhat lacking for the lower three EIAs. For these cases, the model downwind response (relative $\mathrm{WD}=180^{\circ}$ ) is progressively underestimated (at the $0.1 \mathrm{~dB}$ level), and the model fit with the empirical measurements for relative WD 
of $270^{\circ}-360^{\circ}$ disagree at the $0.2 \mathrm{~dB}$ level. Since both the $\mathrm{Ku}$ and $\mathrm{Ka}$ models have issues with this same relative WD range, the empirical measurements are suspect. Further, the model has an even symmetry with relative WD, whereas the empirical measurements have not. The reason for this anomaly is not understood, but given the low EIA, one possible explanation is the effect of ocean wave swell, which has not been considered in this analysis.

The relative difference between the $\mathrm{Ku}$ and $\mathrm{Ka}$ band $\sigma^{0}$ directional residual $\left(\sigma_{\mathrm{Ku} \text {-residual }}^{0}[d B]\right.$ $\left.-\sigma_{K a-r e s i d u a l}^{0}[d B]\right)$, is given in Figure 15 as a function of relative wind direction for the WS averaged over 6-14 m/s at different EIAs. As shown, the maximum difference occurs at the upwind, downwind and crosswind directions which is also a function of the EIA. Now consider the delta- $\sigma^{0}$ residual, calculated at upwind, downwind and crosswind for an EIA $\sim 16^{\circ}$, as a function of WS (given in Figure 16). At the downwind direction, the KaPR has a higher wind direction signal than KuPR for all WS, whereas for the upwind and crosswind, the polarity of the difference depends on WS range.
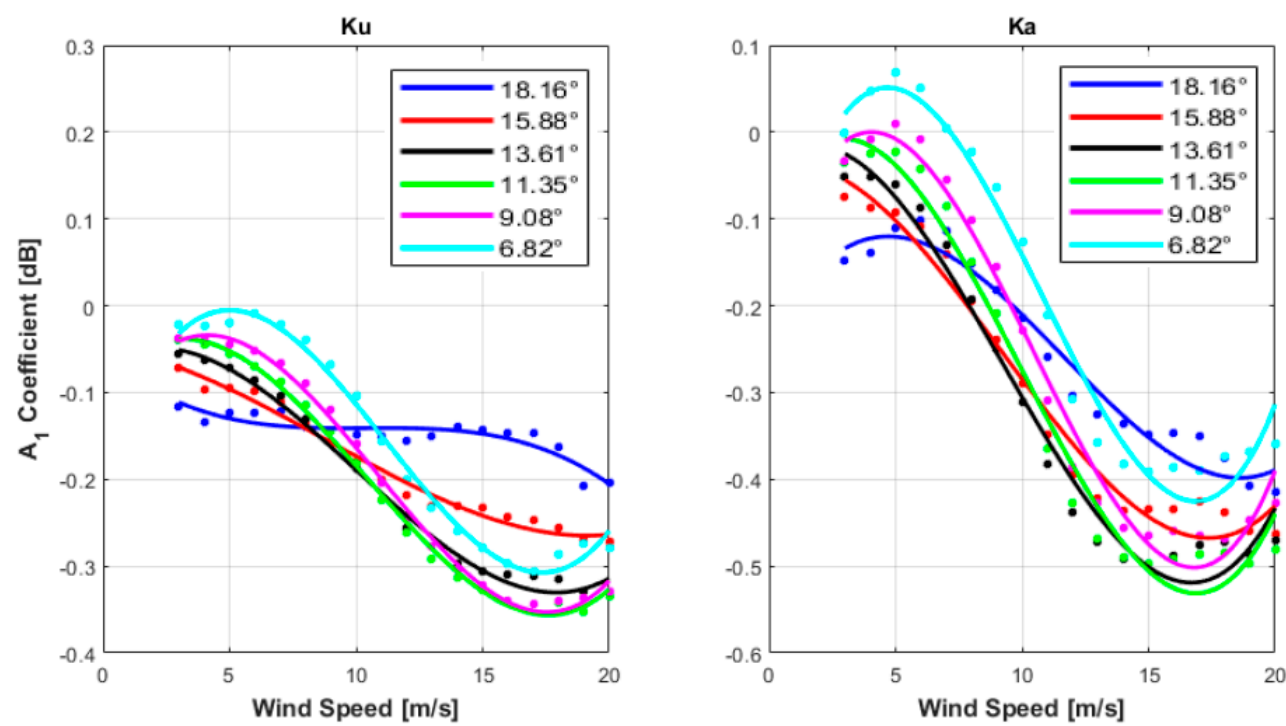

Figure 11. $A_{1}$ coefficient of $\mathrm{KuPR}(\mathbf{l e f t})$ and $\mathrm{KaPR}$ (right) $\sigma^{0}$ models (in $\mathrm{dB}$ ) as a function of wind speed at different earth incidence angles. The symbols are Fourier coefficients while the solid lines represent their 3rd order regression fits.
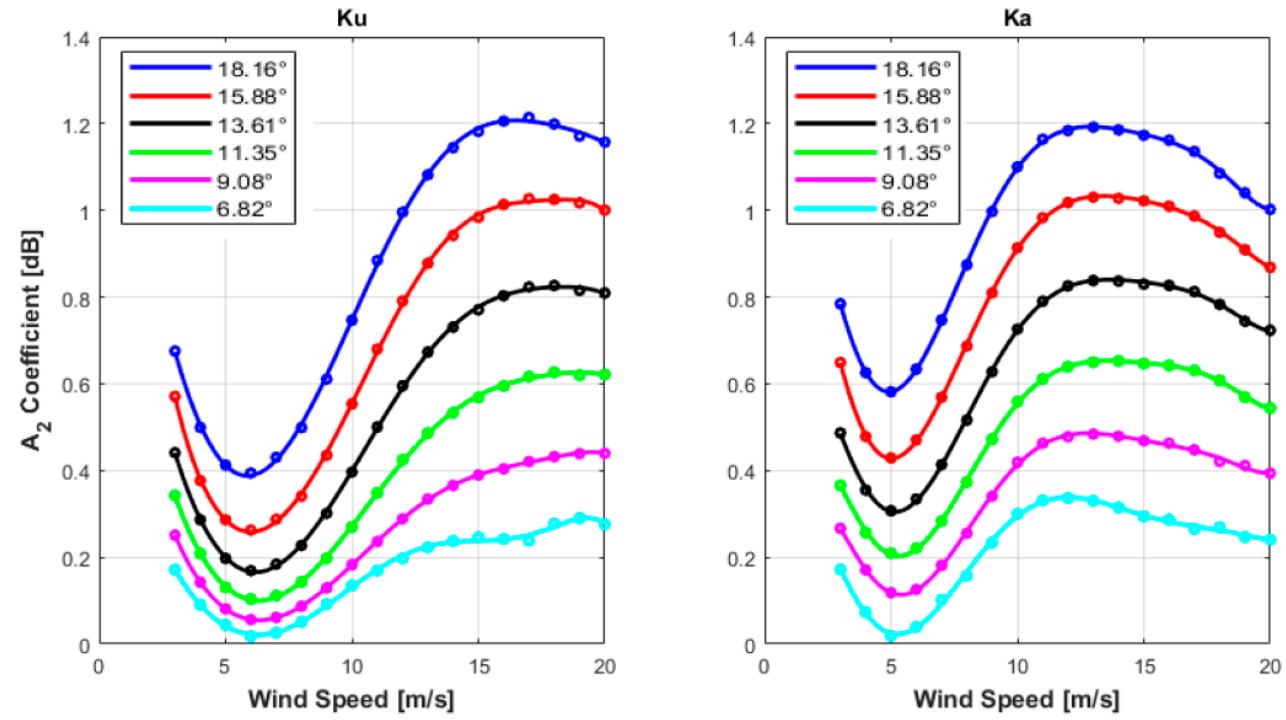

Figure 12. $A_{2}$ coefficient of $\mathrm{KuPR}(\mathbf{l e f t})$ and $\mathrm{KaPR}$ (right) $\sigma^{0}$ models (in $\mathrm{dB}$ ) as a function of wind speed at different earth incidence angles. The symbols are Fourier coefficients while the solid lines represent their 7 th order regression fits. 

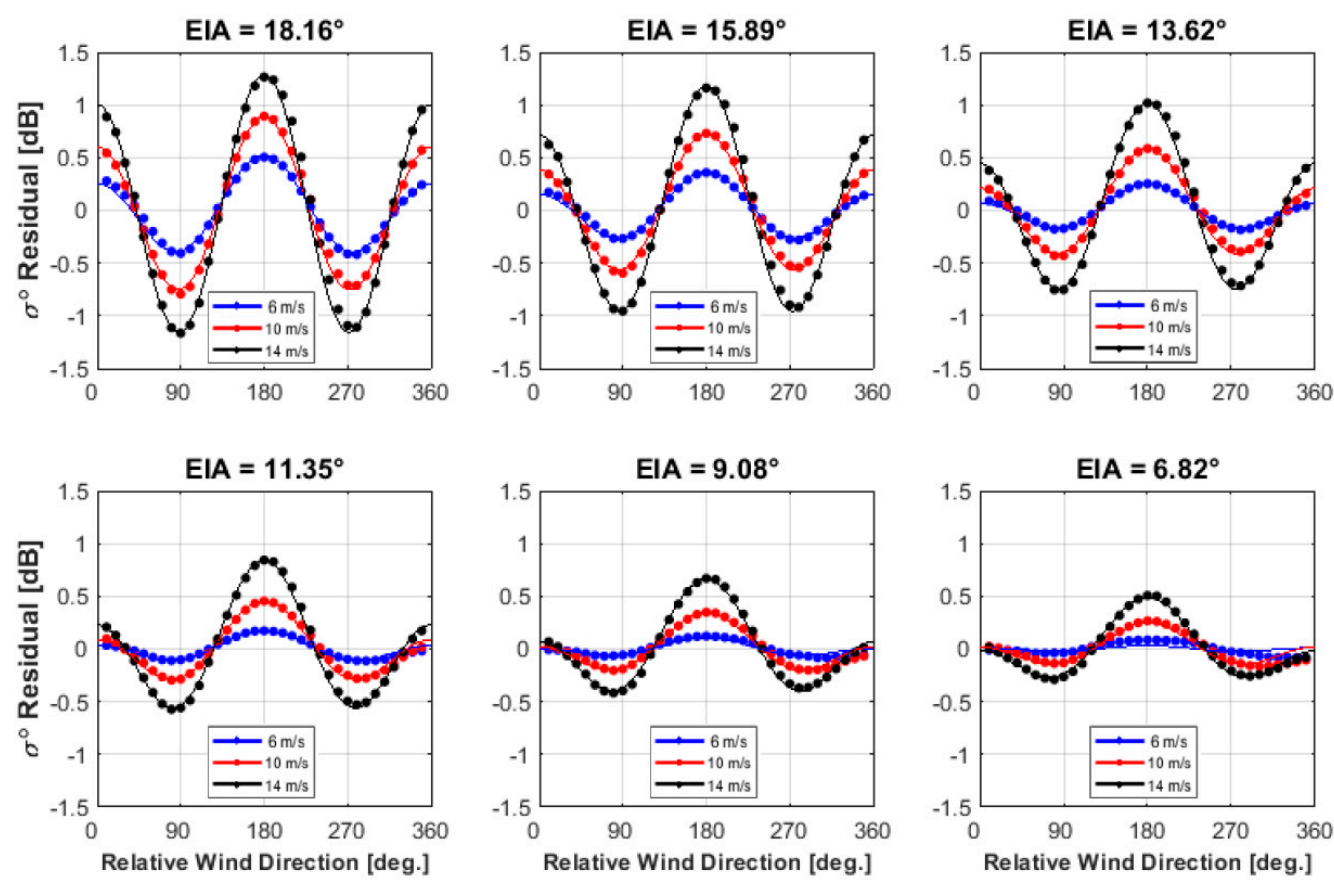

Figure 13. $\mathrm{KuPR} \sigma^{0}$ directional anisotropy (in $\mathrm{dB}$ ) as a function of relative wind direction $(\chi)$, for three different WS values: $6 \mathrm{~m} / \mathrm{s}$ (blue), $10 \mathrm{~m} / \mathrm{s}$ (red), and $14 \mathrm{~m} / \mathrm{s}$ (black) at different earth incidence angles. The symbols are bin average while the solid lines represent their second-order Fourier fits.
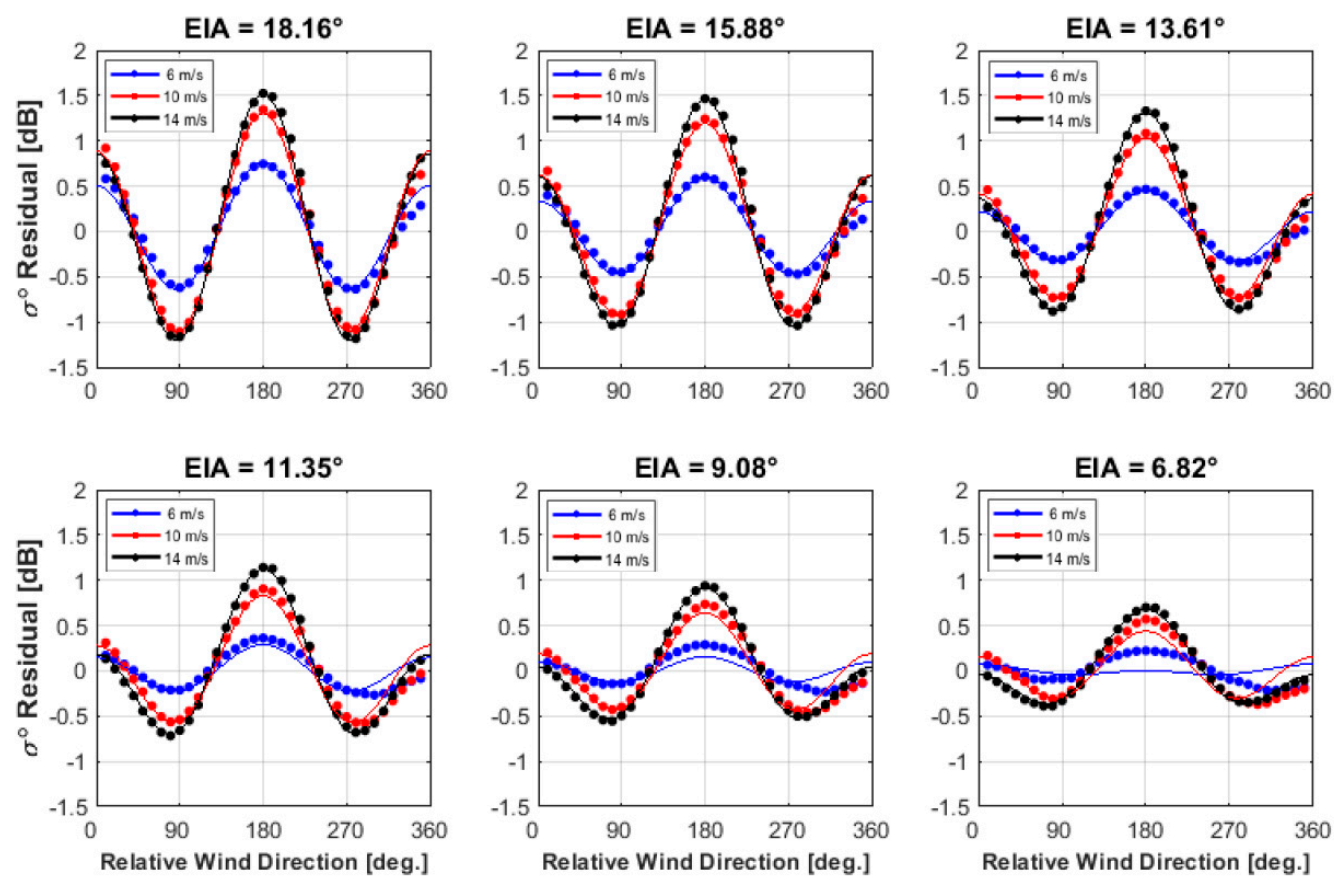

Figure 14. KaPR $\sigma^{0}$ directional anisotropy (in $\mathrm{dB}$ ) as a function of relative wind direction $(\chi)$, for three different WS values: $6 \mathrm{~m} / \mathrm{s}$ (blue), $10 \mathrm{~m} / \mathrm{s}$ (red), and $14 \mathrm{~m} / \mathrm{s}$ (black) at different earth incidence angles. The symbols are bin average while the solid lines represent their second-order Fourier fits. 


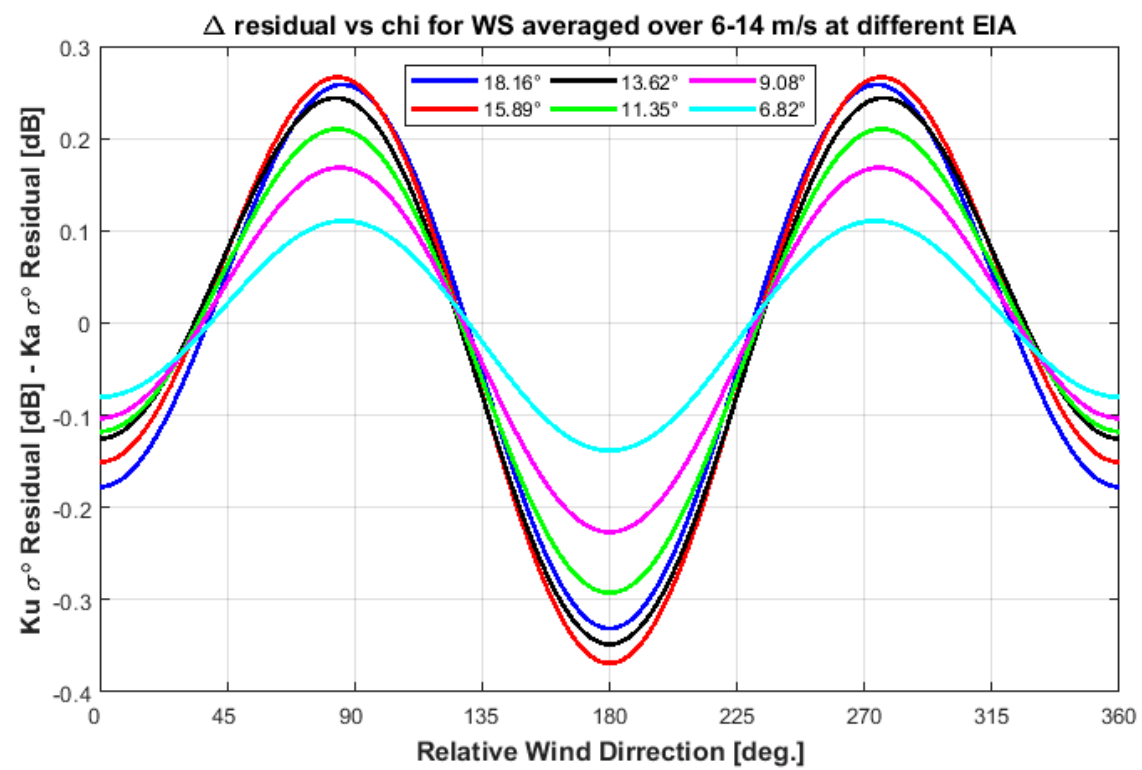

Figure 15. Delta residual (in $\mathrm{dB}$ ) between $\mathrm{KuPR}$ and $\mathrm{KaPR} \sigma^{0}$ directional anisotropy as a function of relative wind direction $(\chi)$ at different EIAs, for wind speed averaged over 6-14 m/s.

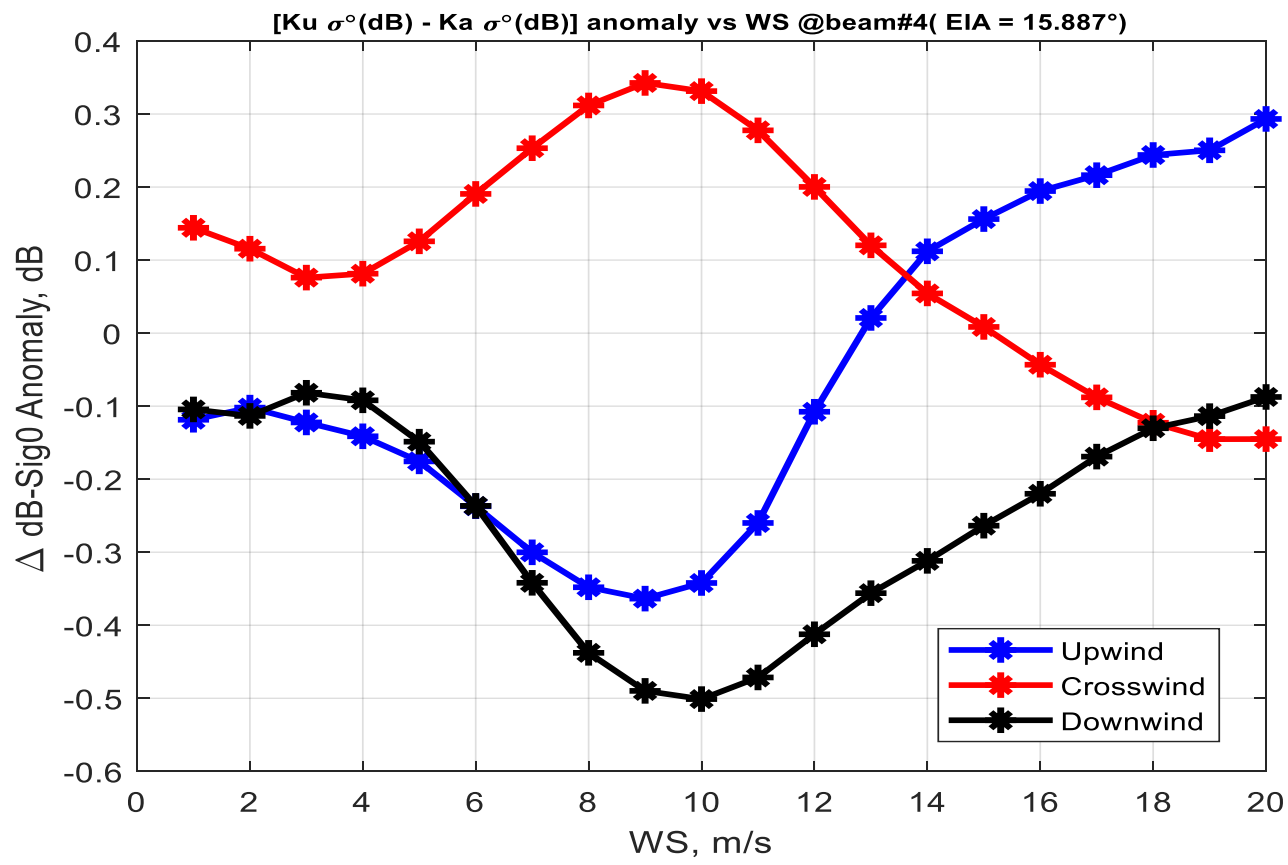

Figure 16. Delta residual (in $\mathrm{dB}$ ) between $\mathrm{KuPR}$ and KaPR $\sigma^{0}$ directional anisotropy as a function of wind speed for upwind, downwind, and crosswind direction at EIA $\sim=16 \mathrm{deg}$.

\subsubsection{Upwind and Downwind Asymmetry of $\sigma^{0}$}

One of the interesting features of the $\sigma^{0} \mathrm{WD}$ anisotropy at low EIA is that it has an opposite upwind/downwind asymmetry compared to the conventional scatterometers that operate at moderate incidence angles $\left(20^{\circ}-70^{\circ}\right)$. As shown in Figures 13 and 14, DPR measures a higher $\sigma^{0}$ from the downwind direction than that from the upwind direction, and $2 A_{1}$ is the measure of the peak-to-peak upwind/downwind asymmetry. The differences between downwind and upwind $\sigma^{0}$ measurements, separately for both KuPR and KaPR as a function of WS: $3-20 \mathrm{~m} / \mathrm{s}$, are shown in Figure 17 for six different EIAs: $6.8^{\circ}-18.2^{\circ}$, and it is noted that for all EIAs, the measured $\sigma^{0}$ asymmetry increases with WS of 6-16 m/s. Chu et al. (2012) [12] also presented similar results for TRMM KuPR and 
Mouche et al. (2006) [27] reported the same trends of asymmetries for a $C$ band radar at low incidence angle. However, this paper presents new information concerning a higher upwind/downwind asymmetry for Ka band compared to the Ku band. For example, at EIA $\sim 12^{\circ}$, the Ku band asymmetry is about $0.7 \mathrm{~dB}$ for a WS of $16 \mathrm{~m} / \mathrm{s}$, while it is $>1 \mathrm{~dB}$ for Ka band for the same EIA and WS.
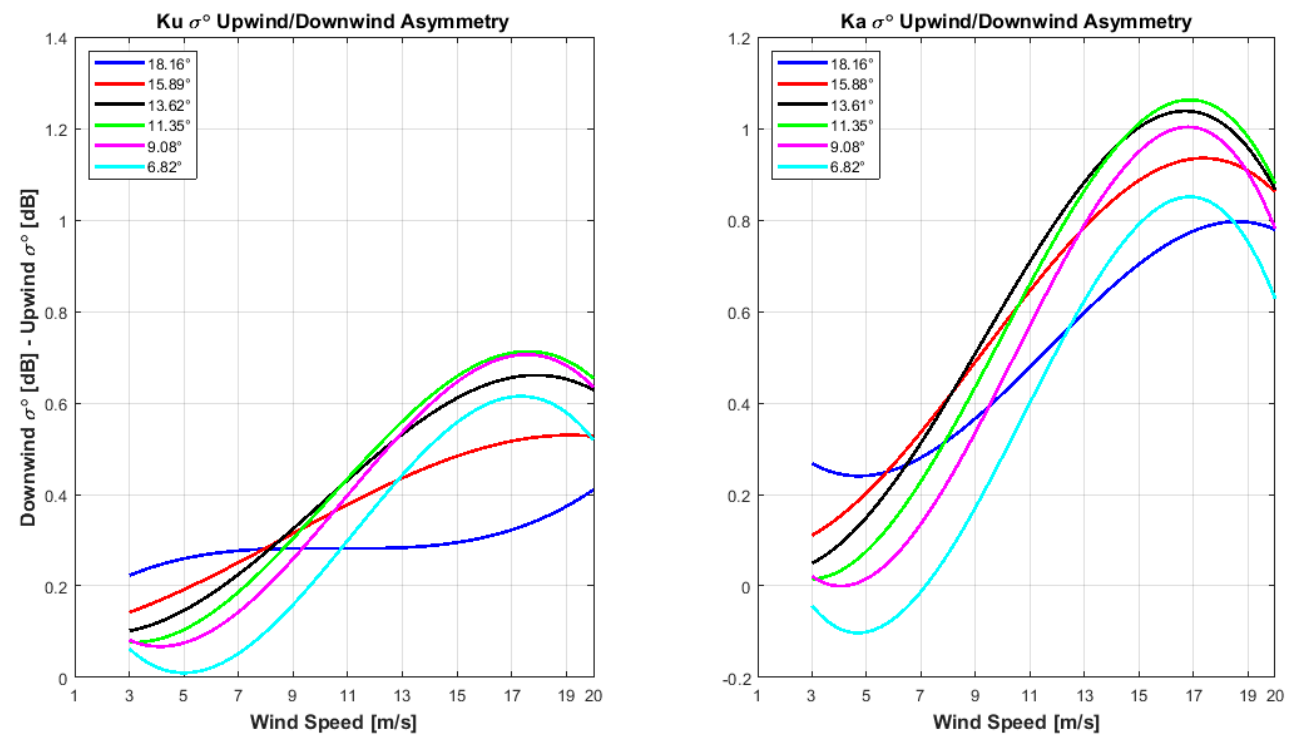

Figure 17. Peak-to-peak KuPR (left) and KaPR (right) $\sigma^{0}$ downwind/upwind asymmetry (in dB) as a function of WS at different EIAs.

\subsubsection{Downwind and Crosswind Anisotropy of $\sigma^{0}$}

For scatterometers operating at moderate EIAs, the $A_{2}$ coefficient in Equations (2) and (5), usually defines the peak-to-peak (upwind to crosswind) anisotropy of $\sigma^{0}$. However, for this low EIA range, since $A_{1}$ is negative and not negligible, backscatter response at the downwind direction is the sum of $A_{1}$ and $A_{2}$. Therefore, the peak-to-peak anisotropy for this EIA range is defined downwind to crosswind which is $>2 A_{2}$. Figure 18 shows the peak-to-peak $\sigma^{0}$ anisotropy for $\mathrm{Ku}$ and Ka bands, as a function of WS for different EIAs. Additionally, Figure 19 shows the same results as a function of EIA for WS: 6-18 m/s. As previously discussed, the shape of this curve follows that of the $A_{2}$ coefficient for both WS and EIA.

\subsection{SST Dependency of $\sigma^{0}$}

In previous research [18], it was concluded that the SST has a small but significant effect on the observed ocean $\sigma^{0}$ at Ku band; but in this paper, these SST effects were not explicitly identified in the development of the three dimensional (3D) GMF $=f(W S, W D, E I A) \mathrm{Ku}$ - and Ka-bands. Unfortunately, the available $\sigma^{0}$ match-up datasets have insufficient observations for the development of a $4 \mathrm{D} G M F=f(W S, W D, S S T, E I A)$; however, a somewhat qualitative assessment of the impact of SST on in the GMFs are presented below.

At low microwave frequencies $(1-8 \mathrm{GHz})$, sea surface temperature affects the dielectric constant of sea water and the resulting Fresnel reflection coefficient; however, at $\mathrm{Ku}$ and Ka bands this effect is weak [24]. On the other hand, SST also affects the surface tension and viscosity of the sea water, both of which control the amplitude of the capillary wave spectral region of the sea surface roughness. For the low wind speed regime $(\sim W S<6 \mathrm{~m} / \mathrm{s})$, surface tension dominates the capillary wave spectrum; whereas for higher WS, wave breaking occurs and viscosity then plays a significant role in controlling the roughness. Thus, surface tension and viscosity, which tend to reduce surface roughness, both decrease with increasing SST. As a result, ocean $\sigma^{0}$ increases with SST, and V-polarized signals 
exhibit larger dependencies on SST than H-pol signals [18]. Since GPM DPR measurements are both $\mathrm{H}$ pol, this paper presents only SST impacts on $\mathrm{H}$ pol at low incidence angles.
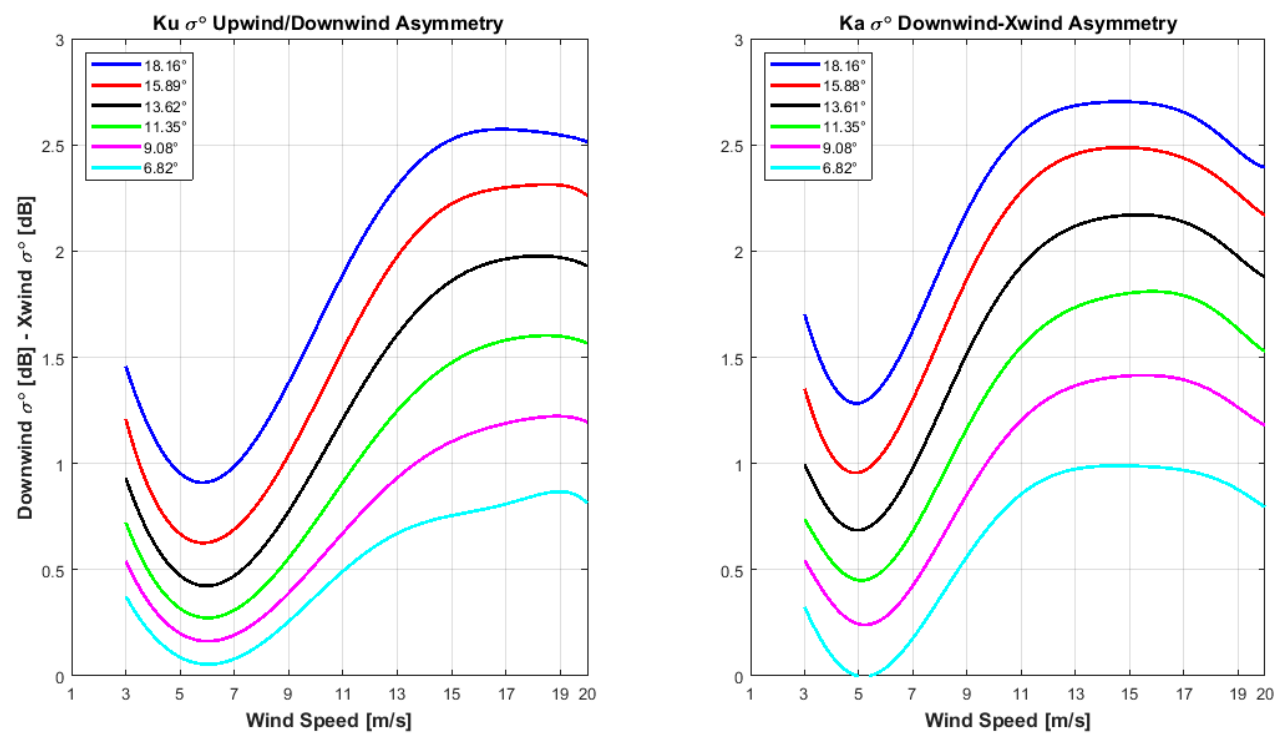

Figure 18. Peak-to-peak KuPR(left) and KaPR (right) downwind/crosswind $\sigma^{0}$ anisotropy (in $\mathrm{dB}$ ) as a function of WS at different EIAs.
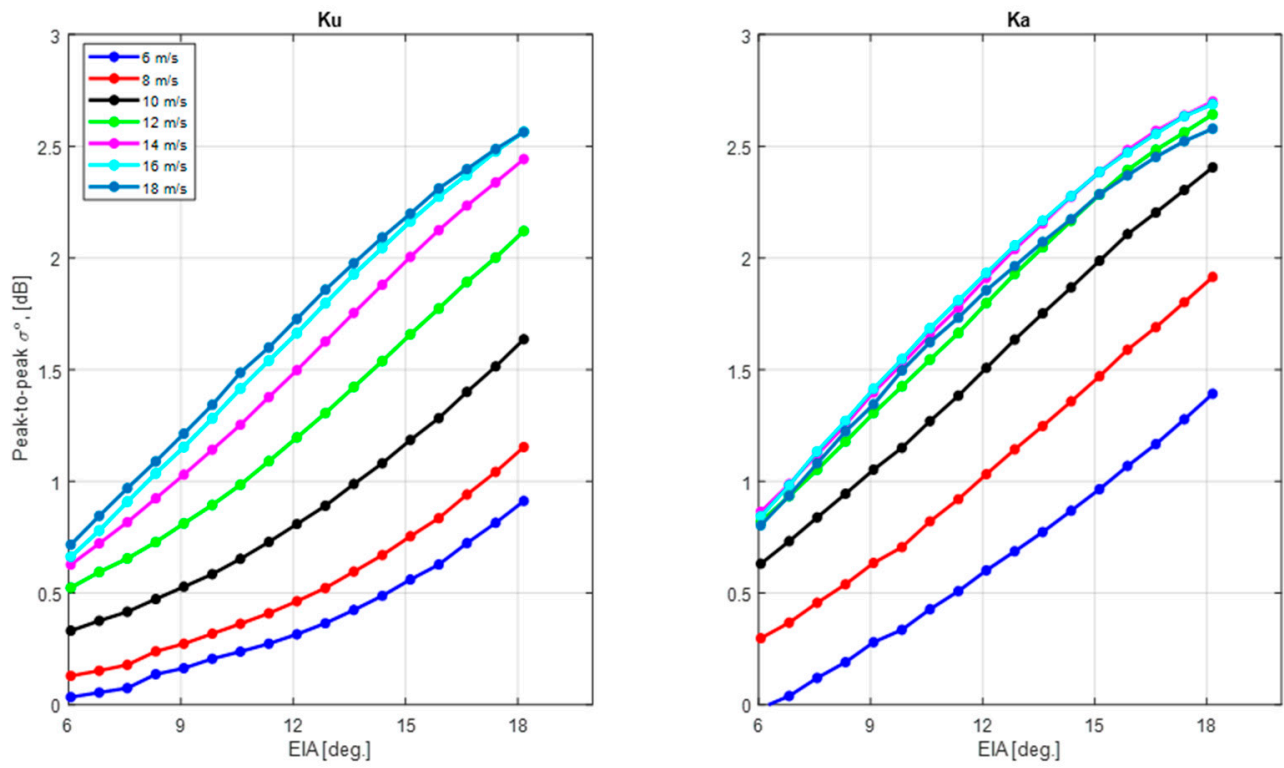

Figure 19. Peak-to-peak KuPR (left) and KaPR (right) downwind/crosswind $\sigma^{0}$ anisotropy as a function of EIA for different WS values.

Thus, the dependence of $\sigma^{0}$ on SST was empirically characterized for both $\mathrm{Ku}$ - and Ka-bands as a function of EIA, WS and WD, using the following statistical procedure. For the EIA investigation, the $\sigma^{0}$ values, in linear power ratio units, were bin averaged (over all WS and WD) in $1{ }^{\circ} \mathrm{C}$ steps of SST $0-30^{\circ} \mathrm{C}$. Next, the binned averages were normalized to the corresponding $\sigma^{0}$ values at $15 \mathrm{C}$, and results presented in Figure 20 show that there is an approximately linear dependence of the relative $\sigma^{0}$ on SST that is independent of EIA beam positions at both frequencies. However, as expected, the SST dependency is significantly stronger ( $>2 \times$ slope) for Ka band. For example, for an EIA $=9^{\circ}$, the overall variation of mean $\sigma^{0}$ with SST over the range $0-30{ }^{\circ} \mathrm{C}$ is $< \pm 5 \%$ at $\mathrm{Ku}$, whereas it is $> \pm$ $10 \%$ for $\mathrm{Ka}$. 

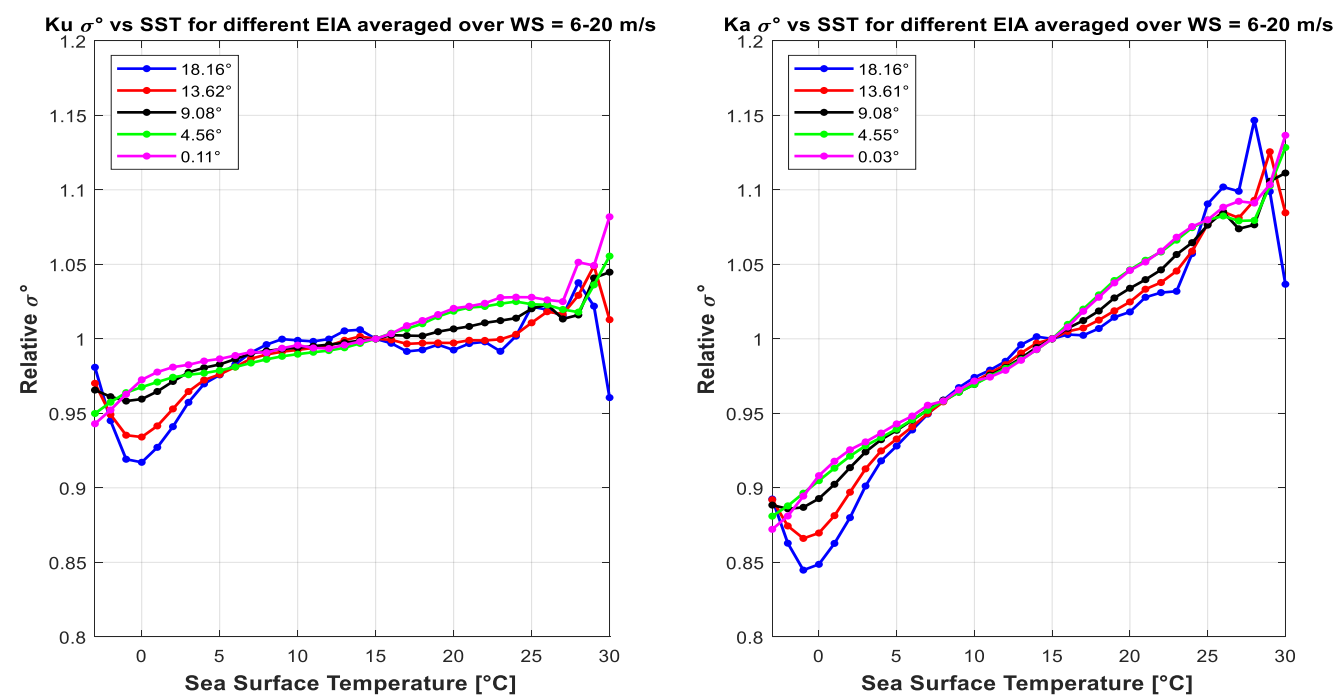

Figure 20. Relative sea surface temperature (SST) dependence of KuPR (left) and KaPR (right) $\sigma^{0}$ at different EIAs over averaged WS.

Next, these SST binned normalized $\sigma^{0}$ data were sorted and averaged (separately for $\mathrm{Ku}$ and $\mathrm{Ka}$ ) over WS values of 4, 8 and $12 \mathrm{~m} / \mathrm{s}$ ranges, and the results are presented in Figure 21 for EIAs of $0.1^{\circ}, 9.8^{\circ}$ and $18.6^{\circ}$. Here, the results are similar to Figure 20 (averaged over all WS); however, there is also a slight WS dependence as noted by the separation of the curves. This is especially notable at the higher EIA that we suspect may be attributed to the WD effects presented next.

Next, changes in the GMF relative wind direction response due to SST were assessed using $\sigma^{0}$ data (not normalized), but here only the outer most beam position (EIA $=18^{\circ}$ ) was selected since it has the largest anisotropy. The results are shown in Figure 22 for SST of 5 and $25^{\circ} \mathrm{C}$ as a function of relative WD for WS values of 8,10 and $12 \mathrm{~m} / \mathrm{s}$. For Ku-band, there appears to be no SST effects and the relative WD patterns are essentially identical; on the other hand, at Ka-band the effect is small but significant. It appears that the $\sigma^{0} \mathrm{WD}$ pattern is unchanged except for a small increase in the mean (dc offset), which is consistent with the observation presented in Figure 20.

Finally, the SST impacts, on the mean value of $\mathrm{KuPR}$ and $\mathrm{KaPR} \sigma^{0}$, are presented in Figure 23 as in set of 2D images for observed ranges of SST and WS. The color scale represents the mean $\sigma^{0}$ relative to corresponding $\sigma^{0}$ at $15^{\circ} \mathrm{C}$. As shown, for WS $>5 \mathrm{~m} / \mathrm{s}$, the mean backscatter at both band increases with SST; however, the contrast is significantly higher at Ka-band. For WS $\sim 5 \mathrm{~m} / \mathrm{s}$, the trend is opposite at both bands. These SST dependent relative weights can be used as a correction factor to account for the SST impacts on the GMF. One such approach was used by [28] to correct and validate NSCAT-5 GMF. For the DPR model of this paper (Equation (2)), this can be implemented as follows,

$$
\sigma_{\text {corrected }}^{0}(f)=\mathrm{W}(\mathrm{SST}, \mathrm{WS}) x \sigma_{\text {linear }}^{0}(f)
$$

where $\sigma_{\text {linear }}^{0}(f)$ is $\sigma^{0}$ model in linear scale, and W is SST-impact correction factor which can determined from the tables such as presented in Figure 23 for different EIA beam positions. Sample correction factors, $\mathrm{W}(\mathrm{SST}, \mathrm{WS})$, for $\mathrm{Ku}$ - and Ka-band models at EIA $=18^{\circ}$ are given in the Tables A5 and A6, respectively, in Appendix B. 

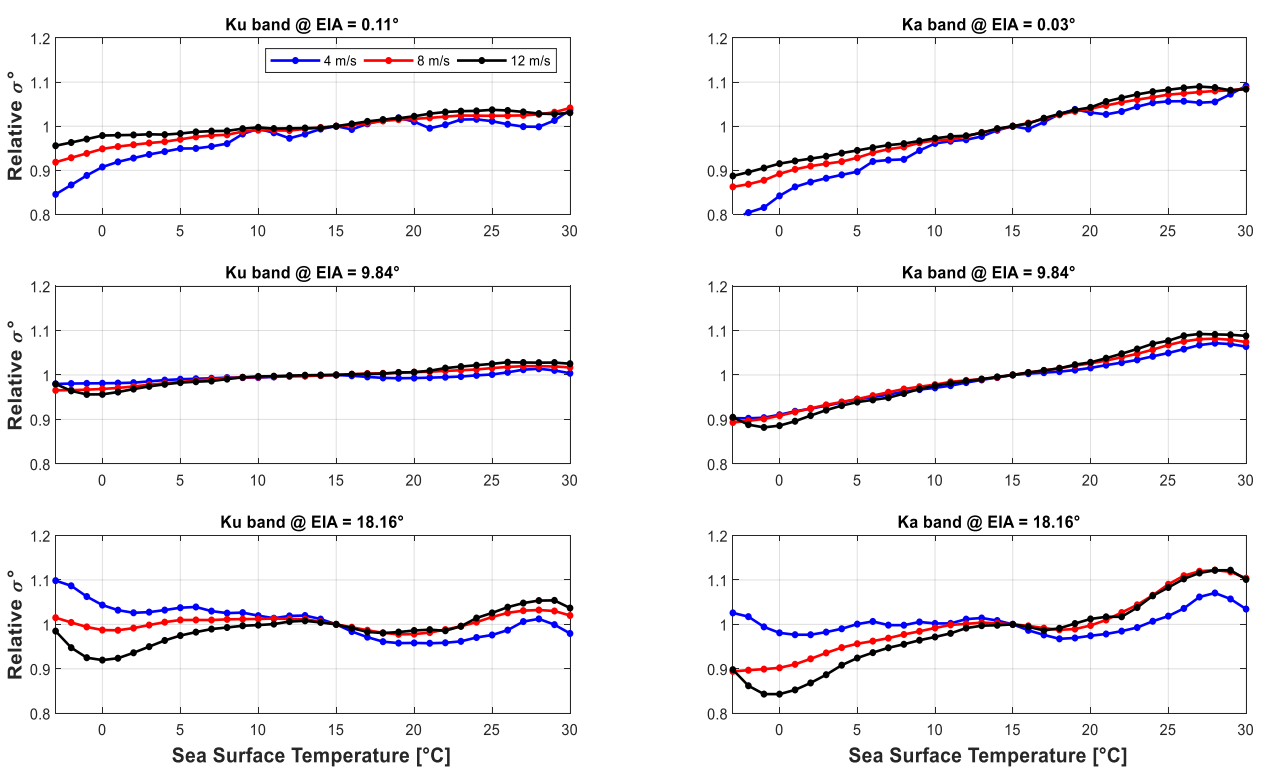

Figure 21. Wind speed impacts on KuPR and KaPR $\sigma^{0}$ SST dependency at different EIAs.
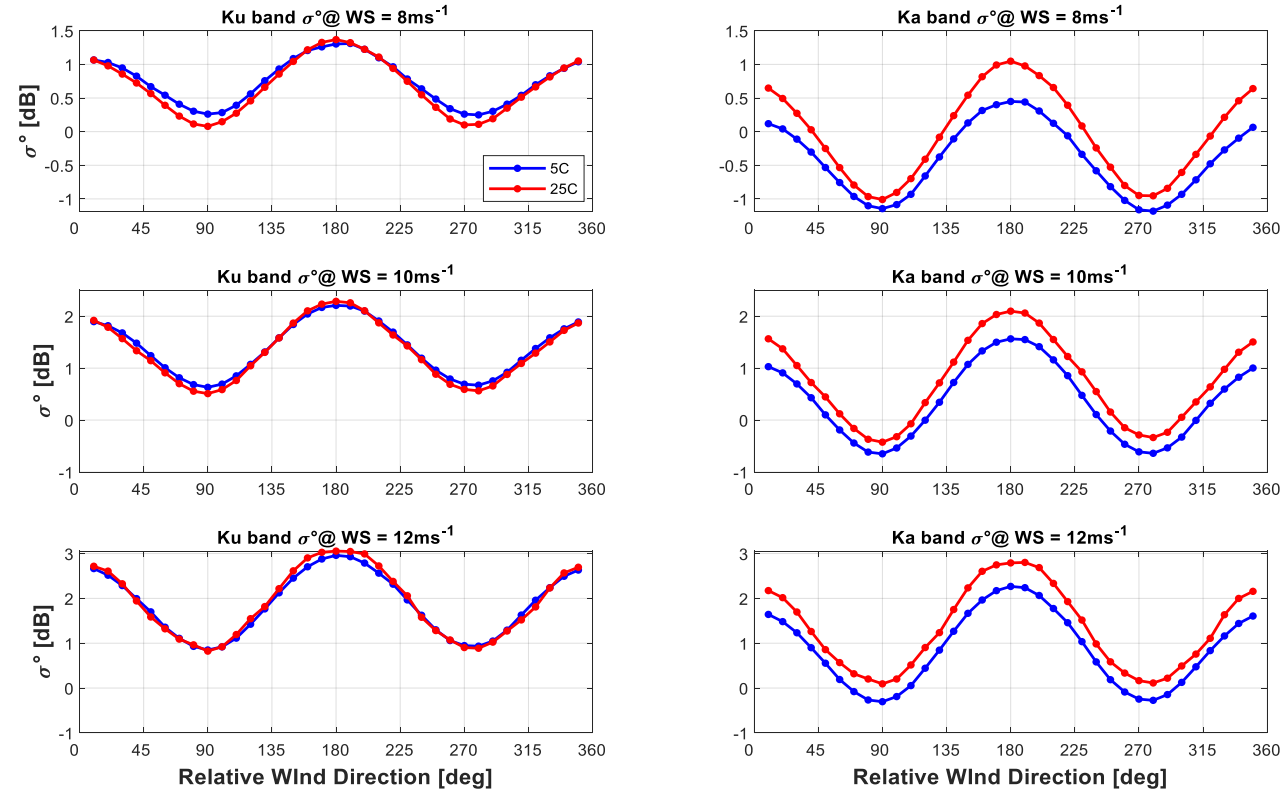

Figure 22. SST impacts on KuPR and KaPR $\sigma^{0}$ model functions at different WS values at an EIA of $18^{\circ}$. 

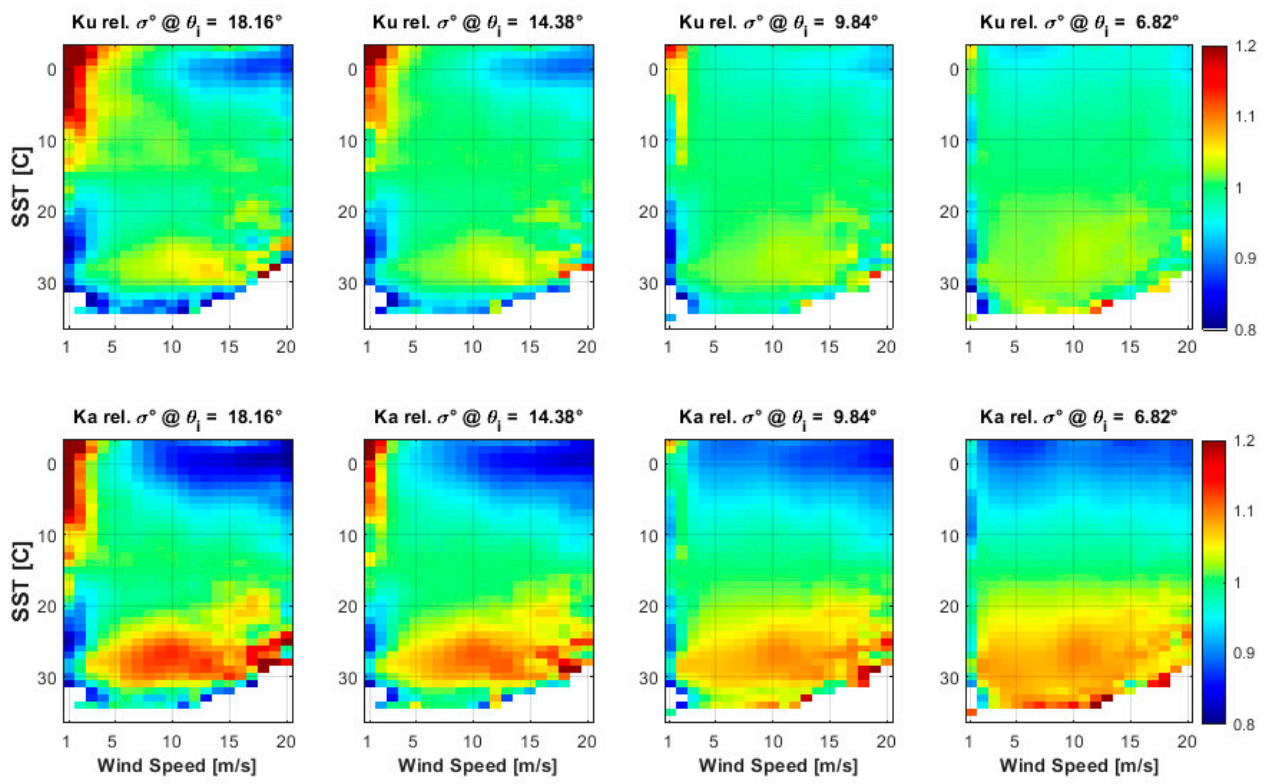

Figure 23. Relative SST impacts on KuPR (top) and KaPR (bottom) mean $\sigma^{0}$.

\section{Discussion}

The dual-frequency precipitation radar (DPR) onboard GPM core satellite provides coincident $\mathrm{Ku}$ and $\mathrm{Ka}$-band $\sigma^{0}$ measurements over a wide near-nadir EIA range. This study leveraged the unique opportunity to perform a comprehensive investigation on nearnadir ocean surface backscatter characteristics using measurements from $\mathrm{Ku}$ and Ka-band radars that were identical in geometry and calibration, and thus derived the corresponding backscatter models. This is unprecedented and the results are significant because the amount of data used was reliably large and all the measurements were precisely collocated in space and time. More importantly, the same surface truth data (WS, WD, and SST) and exactly the same data analysis procedure were applied to characterize the wind vector and SST dependency of $\mathrm{Ku}$ - and Ka-band radar backscatter for a full EIA range of $\pm 18^{\circ}$. Although the Ku-band results are consistent with the previous studies, the comparison with Ka-band are somewhat unique. Both GMFs were fully explored and results were presented in parallel, so that one can easily compare key characteristics at both the bands for utilization in scatterometry from space.

The trends of WS-only dependency of Ku- and Ka-band radar backscatter at the EIA ranges under consideration were shown to be similar in the way that ocean surface radar backscatter increases (for higher EIA) and decreases (for lower EIA) monotonically with WS, but the slope of increase flattens as the WS increases. The difference of mean $\sigma^{0}$ between $\mathrm{Ku}$ - and $\mathrm{Ka}-$ band is dependent on both WS and EIA, and within around $3 \mathrm{~dB}$ for WS $1-20 \mathrm{~m} / \mathrm{s}$ and EIA $7-18^{\circ}$. The difference is reduced with increasing EIA, and with WS, it is lower at moderate WS, but increases at both higher and lower WS. However, the directional sensitivity of Ka-band ocean radar backscatter was found to be higher than Kuband directional sensitivity for low to moderate WS regime. This is particularly significant in path attenuation correction, in the calibration of radars, and also in considering future missions for ocean wind vector remote sensing at Ka-band. However, as shown earlier, saturation of directional anisotropy at Ka-band occurs at relatively lower WS, which might limit the use of Ka band for remote sensing of higher WS. Moreover, the SST effects were shown to be substantially higher at Ka-band than that at Ku-band. In recent years, the SST impact on Ku-band GMFs and on subsequent wind retrieval has raised a concern. Different ways of correcting existing GMFs and also developing fully SST-dependent GMFs are underway. The SST dependency presented here for Ku-band GMFs is consistent with the developing literature, and the results presented for Ka-band are also consistent with theories. Therefore, taking SST impacts into consideration is recommended for both bands. 
A simple way to include that is given in Equation (8), and the corresponding correction tables are provided in Appendix B.

The Fourier cosine series model that has been used to develop conventional scatterometer GMFs was also shown to be applicable to radar backscatter model at low EIA. However, the distinct upwind and downwind asymmetry was also made clear for both bands. WS-dependent model coefficients were provided for both bands, which can be applied to model ocean radar backscatter at $\mathrm{Ku}$ - and $\mathrm{Ka}$ - band with prior WS information. This can be used to estimate ocean radar backscatter for various applications, one example could be to produce coincident Ka-band backscatter at the outer swat beam positions for initial phase of GPM missions when KaPR made measurements over $125 \mathrm{~km}$ central swath only. This would be useful for implementing DPR dual frequency algorithm for entire GPM lifetime.

Although the Ku-band scatterometry at moderate incidence angle has already been established, this paper explores the potential of Ka-band scatterometry. In addition, it has also proved the feasibility of $\mathrm{Ku}$ - and Ka-band scatterometry at lower EIAs. If the DPR onboard GPM had multiple azimuth views, it would have been possible to retrieve wind vector from GPM DPR. Since both PRs only have a single azimuth look, it is not currently possible to retrieve unique wind direction from DPR. On the other hand, simultaneously, there is the conically scanning GMI, which measure passive brightness temperatures $(\mathrm{Tb})$ with different azimuth diversity. Current studies are investigating the feasibility of combined active-passive remote sensing ocean wind vectors from GPM, leveraging the directional anisotropy of both active and passive ocean measurements and their azimuth diversity [29]. As GPM is in non-sun-synchronous orbit, this approach has a high scientific potential to provide full diurnal sampling of OVW, which is not possible with conventional scatterometers flying in polar sun-synchronous orbits. As mentioned by some studies [9-11], one possible difficulty concerns the effects of significant ocean wave height $(\mathrm{SWH})$ and ocean swell, which might be significant at this low EIA range. However, dual-frequency observations, along with collocated ocean wave numerical model forecast should allow correction for these long ocean wave contributions [30]. Therefore, this study will be extended to include ocean sea state, particularly, the SWH effects on ocean normalized cross section at both $\mathrm{Ku}$ - and Ka-bands for lower EIAs.

\section{Conclusions}

In this paper, we characterized ocean surface normalized radar cross section $\left(\sigma^{0}\right)$ at $\mathrm{Ku}$ - and Ka-band over an EIA range of $\pm 18^{\circ}$ using simultaneous and coincident measurements by dual-frequency precipitation radars (DPR) onboard GPM. Separate geophysical model functions (GMFs) were derived that characterized the wind speed dependence and azimuthal anisotropy of $\sigma^{0}$ over the above mentioned EIA range. A detailed comparison, of the two GMFs, was presented and differences were explicitly documented in GMF coefficients Appendix A. Additionally, SST effects on $\mathrm{Ku}$ - and $\mathrm{Ka}-\mathrm{band} \sigma^{0}$ were assessed, and a simple approach, to incorporate these effects into corresponding GMFs, was presented. It was discovered that Ka-band has higher directional sensitivity for low-to-moderate WS, and the SST impact was also found to be more substantial at Ka-band than at Ku-band. The possibilities of dual-band ocean wind vector remote sensing at moderate EIAs, and also from GPM, were discussed and finally, the scope of future research directions is given. This study will significantly improve the understanding of the Ka-band, as well as enhance the knowledge of Ku-band scatterometry at near-nadir incidence angles.

Author Contributions: Conceptualization, A.H. and W.L.J.; methodology, A.H.; software, A.H.; validation A.H., and W.L.J.; formal analysis, A.H.; investigation, A.H.; resources, A.H.; data curation, A.H.; writing—original draft preparation, A.H.; writing—review and editing, W.L.J., and A.H.; visualization, A.H.; supervision, W.L.J.; project administration, W.L.J. Both the authors have read and agreed to the published version of the manuscript. 
Funding: This research was conducted at the University of Central Florida without external funding. Article processing charges were provided in part by the UCF College of Graduate Studies Open Access Publishing Fund.

Data Availability Statement: The DPR data used in this study are openly available at the NASA PPS data archive in https:/ / arthurhou.pps.eosdis.nasa.gov, accessed on 15 April 2021. The GMI data were produced by Remote Sensing Systems and sponsored by NASA Earth Science funding. The data are available at www.remss.com, accessed on 15 April 2021. The model functions presented in this paper along with their corresponding bin average measurements, polynomial coefficients and SST correction factors are publicly available in https://github.com/HossanAlamgir/Ku-and-KaBand-Ocean-Surface-Radar-Backscatter-Model-Functions-at-Low-Incidence-Angles.git, accessed on 15 April 2021.

Acknowledgments: The authors would like to thank the Precipitation Processing System (PPS) at the NASA Goddard Space Flight Center for providing the GPM DPR data, Remote Sensing Systems for providing GMI data, and Department of Atmospheric Science at Colorado State University for providing access to their server for ERA5 data. The authors would also like to thank four anonymous reviewers for their valuable comments to improve the manuscript.

Conflicts of Interest: The authors declare no conflict of interest.

\section{Appendix A}

Table A1. Polynomial coefficients for Ku- and Ka-band $A_{0}$ model in dB (Equation (4)).

\begin{tabular}{|c|c|c|c|c|c|c|c|c|c|c|}
\hline \multirow{2}{*}{ Beam No } & \multicolumn{5}{|c|}{$\mathbf{K u}$} & \multicolumn{5}{|c|}{$\mathbf{K a}$} \\
\hline & EIA & $a_{01}$ & $a_{02}$ & $a_{03}$ & $a_{04}$ & EIA & $a_{01}$ & $a_{02}$ & $a_{03}$ & $a_{04}$ \\
\hline 1 & 18.16 & 0.23 & -5.69 & 16.54 & -9.71 & 18.16 & -2.92 & 0.01 & 14.62 & -11.28 \\
\hline 2 & 17.41 & 0.70 & -6.96 & 16.95 & -8.53 & 17.40 & -2.25 & -1.64 & 15.01 & -9.92 \\
\hline 3 & 16.64 & 1.01 & -7.82 & 16.97 & -7.35 & 16.64 & -1.63 & -3.14 & 15.25 & -8.62 \\
\hline 4 & 15.89 & 1.15 & -8.21 & 16.60 & -5.99 & 15.88 & -1.08 & -4.46 & 15.32 & -7.23 \\
\hline 5 & 15.13 & 1.41 & -8.95 & 16.51 & -4.68 & 15.13 & -0.51 & -5.81 & 15.41 & -6.03 \\
\hline 6 & 14.38 & 1.69 & -9.69 & 16.40 & -3.45 & 14.37 & 0.09 & -7.26 & 15.60 & -4.79 \\
\hline 7 & 13.62 & 1.78 & -9.92 & 15.85 & -2.12 & 13.61 & 0.69 & -8.70 & 15.79 & -3.40 \\
\hline 8 & 12.86 & 1.73 & -9.72 & 14.89 & -0.63 & 12.86 & 1.20 & -9.92 & 15.83 & -2.20 \\
\hline 9 & 12.10 & 1.84 & -10.02 & 14.42 & 0.72 & 12.10 & 1.73 & -11.21 & 15.93 & -0.92 \\
\hline 10 & 11.35 & 1.72 & -9.64 & 13.33 & 2.14 & 11.35 & 2.21 & -12.39 & 15.98 & 0.28 \\
\hline 11 & 10.59 & 1.57 & -9.12 & 12.12 & 3.55 & 10.59 & 2.67 & -13.50 & 16.01 & 1.45 \\
\hline 12 & 9.84 & 1.31 & -8.34 & 10.70 & 5.07 & 9.84 & 3.04 & -14.37 & 15.86 & 2.74 \\
\hline 13 & 9.08 & 1.07 & -7.55 & 9.27 & 6.51 & 9.08 & 3.46 & -15.43 & 15.90 & 3.70 \\
\hline 14 & 8.33 & 0.62 & -6.23 & 7.41 & 7.98 & 8.33 & 3.83 & -16.29 & 15.77 & 4.97 \\
\hline 15 & 7.57 & 0.33 & -5.25 & 5.81 & 9.42 & 7.57 & 4.03 & -16.69 & 15.27 & 5.98 \\
\hline 16 & 6.82 & -0.11 & -3.92 & 3.97 & 10.72 & 6.82 & 4.25 & -17.09 & 14.80 & 6.94 \\
\hline 17 & 6.06 & -0.66 & -2.23 & 1.82 & 12.11 & 6.06 & 4.14 & -16.61 & 13.61 & 8.19 \\
\hline 18 & 5.31 & -1.32 & -0.18 & -0.66 & 13.57 & 5.31 & 3.95 & -15.86 & 12.19 & 9.13 \\
\hline 19 & 4.56 & -2.07 & 2.12 & -3.33 & 14.98 & 4.55 & 3.64 & -14.78 & 10.55 & 10.35 \\
\hline 20 & 3.80 & -2.66 & 3.97 & -5.54 & 16.16 & 3.80 & 3.36 & -13.77 & 9.04 & 11.31 \\
\hline 21 & 3.04 & -3.31 & 5.96 & -7.79 & 17.25 & 3.04 & 3.12 & -12.93 & 7.77 & 12.03 \\
\hline
\end{tabular}


Table A1. Cont.

\begin{tabular}{|c|c|c|c|c|c|c|c|c|c|c|}
\hline \multirow{2}{*}{ Beam No } & \multicolumn{5}{|c|}{$\mathbf{K u}$} & \multicolumn{5}{|c|}{$\mathrm{Ka}$} \\
\hline & EIA & $a_{01}$ & $a_{02}$ & $a_{03}$ & $a_{04}$ & EIA & $a_{01}$ & $a_{02}$ & $a_{03}$ & $a_{04}$ \\
\hline 22 & 2.29 & -4.01 & 8.06 & -10.05 & 18.14 & 2.29 & 2.79 & -11.82 & 6.32 & 13.15 \\
\hline 23 & 1.54 & -4.73 & 10.28 & -12.42 & 19.06 & 1.54 & 2.37 & -10.45 & 4.68 & 13.66 \\
\hline 24 & 0.79 & -5.31 & 12.25 & -14.66 & 19.89 & 0.78 & 2.00 & -9.22 & 3.22 & 14.08 \\
\hline 25 & 0.11 & -6.73 & 17.07 & -19.93 & 21.84 & 0.03 & 0.35 & -4.06 & -1.96 & 16.00 \\
\hline
\end{tabular}

Table A2. Polynomial coefficients for $\mathrm{Ku}$ - and Ka-band $A_{1}$ model in dB (Equation (6)).

\begin{tabular}{|c|c|c|c|c|c|c|c|c|c|c|}
\hline \multirow{2}{*}{ Beam No } & \multicolumn{5}{|c|}{$\mathbf{K u}$} & \multicolumn{5}{|c|}{$\mathrm{Ka}$} \\
\hline & EIA & $a_{11}$ & $a_{12}$ & $a_{13}$ & $a_{14}$ & EIA & $a_{11}$ & $a_{12}$ & $a_{13}$ & $a_{14}$ \\
\hline 1 & 18.16 & -0.0001 & 0.0023 & -0.0243 & -0.0576 & 18.16 & 0.0002 & -0.0072 & 0.0545 & -0.2377 \\
\hline 2 & 17.41 & 0.0000 & 0.0011 & -0.0160 & -0.0694 & 17.4 & 0.0002 & -0.0072 & 0.0458 & -0.1950 \\
\hline 3 & 16.64 & 0.0000 & 0.0002 & -0.0132 & -0.0550 & 16.64 & 0.0002 & -0.0062 & 0.0264 & -0.1137 \\
\hline 4 & 15.89 & 0.0001 & -0.0013 & -0.0043 & -0.0476 & 15.88 & 0.0002 & -0.0054 & 0.0105 & -0.0432 \\
\hline 5 & 15.13 & 0.0001 & -0.0017 & -0.0039 & -0.0363 & 15.13 & 0.0003 & -0.0071 & 0.0214 & -0.0561 \\
\hline 6 & 14.38 & 0.0001 & -0.0029 & 0.0048 & -0.0437 & 14.37 & 0.0003 & -0.0073 & 0.0202 & -0.0352 \\
\hline 7 & 13.62 & 0.0001 & -0.0043 & 0.0163 & -0.0650 & 13.61 & 0.0003 & -0.0085 & 0.0280 & -0.0408 \\
\hline 8 & 12.86 & 0.0002 & -0.0047 & 0.0192 & -0.0664 & 12.86 & 0.0003 & -0.0090 & 0.0308 & -0.0351 \\
\hline 9 & 12.1 & 0.0002 & -0.0056 & 0.0260 & -0.0751 & 12.1 & 0.0004 & -0.0103 & 0.0450 & -0.0640 \\
\hline 10 & 11.35 & 0.0002 & -0.0066 & 0.0356 & -0.0916 & 11.35 & 0.0004 & -0.0116 & 0.0583 & -0.0891 \\
\hline 11 & 10.59 & 0.0002 & -0.0061 & 0.0315 & -0.0780 & 10.59 & 0.0004 & -0.0134 & 0.0768 & -0.1253 \\
\hline 12 & 9.84 & 0.0002 & -0.0068 & 0.0398 & -0.1047 & 9.84 & 0.0005 & -0.0155 & 0.0999 & -0.1827 \\
\hline 13 & 9.08 & 0.0003 & -0.0086 & 0.0572 & -0.1425 & 9.08 & 0.0005 & -0.0152 & 0.0990 & -0.1842 \\
\hline 14 & 8.33 & 0.0003 & -0.0088 & 0.0616 & -0.1510 & 8.33 & 0.0005 & -0.0161 & 0.1110 & -0.2023 \\
\hline 15 & 7.57 & 0.0003 & -0.0111 & 0.0850 & -0.1987 & 7.57 & 0.0005 & -0.0152 & 0.1059 & -0.1826 \\
\hline 16 & 6.82 & 0.0003 & -0.0108 & 0.0836 & -0.1942 & 6.82 & 0.0005 & -0.0170 & 0.1249 & -0.2141 \\
\hline 17 & 6.06 & 0.0003 & -0.0109 & 0.0872 & -0.2043 & 6.06 & 0.0005 & -0.0165 & 0.1229 & -0.1963 \\
\hline 18 & 5.31 & 0.0003 & -0.0105 & 0.0854 & -0.1900 & 5.31 & 0.0005 & -0.0163 & 0.1255 & -0.1987 \\
\hline 19 & 4.56 & 0.0003 & -0.0091 & 0.0722 & -0.1562 & 4.55 & 0.0005 & -0.0148 & 0.1125 & -0.1371 \\
\hline 20 & 3.8 & 0.0003 & -0.0079 & 0.0584 & -0.0945 & 3.8 & 0.0004 & -0.0127 & 0.0952 & -0.0876 \\
\hline 21 & 3.04 & 0.0001 & -0.0040 & 0.0254 & -0.0119 & 3.04 & 0.0004 & -0.0131 & 0.1065 & -0.1298 \\
\hline 22 & 2.29 & 0.0002 & -0.0087 & 0.0932 & -0.2913 & 2.29 & 0.0004 & -0.0143 & 0.1291 & -0.2344 \\
\hline 23 & 1.54 & 0.0003 & -0.0091 & 0.0944 & -0.2678 & 1.54 & 0.0004 & -0.0148 & 0.1487 & -0.3375 \\
\hline 24 & 0.79 & 0.0001 & -0.0053 & 0.0574 & -0.1468 & 0.78 & 0.0004 & -0.0147 & 0.1507 & -0.3238 \\
\hline 25 & 0.11 & -0.0001 & 0.0045 & -0.0434 & 0.1710 & 0.03 & 0.0004 & -0.0141 & 0.1347 & -0.2774 \\
\hline
\end{tabular}


Table A3. Polynomial coefficients for Ku-band $A_{2}$ model in dB (Equation (7)).

\begin{tabular}{|c|c|c|c|c|c|c|c|c|c|}
\hline $\begin{array}{c}\text { Beam } \\
\text { No }\end{array}$ & EIA & $a_{21}$ & $a_{22}$ & $a_{23}$ & $a_{24}$ & $a_{25}$ & $a_{26}$ & $a_{27}$ & $a_{28}$ \\
\hline 1 & 18.16 & $-2.51 \times 10^{-8}$ & $1.37 \times 10^{-6}$ & $-1.89 \times 10^{-5}$ & -0.00013 & 0.00321 & 0.019326 & -0.38819 & 1.591838 \\
\hline 2 & 17.41 & $-3.03 \times 10^{-8}$ & $1.88 \times 10^{-6}$ & $-3.86 \times 10^{-5}$ & 0.000258 & -0.00098 & 0.042961 & -0.45597 & 1.628328 \\
\hline 3 & 16.64 & $-1.13 \times 10^{-7}$ & $8.54 \times 10^{-6}$ & -0.00026 & 0.004169 & -0.04013 & 0.263471 & -1.10123 & 2.343184 \\
\hline 4 & 15.89 & $-1.21 \times 10^{-7}$ & $9.35 \times 10^{-6}$ & -0.00029 & 0.004749 & -0.04628 & 0.298097 & -1.19719 & 2.406955 \\
\hline 5 & 15.13 & $-7.46 \times 10^{-8}$ & $5.58 \times 10^{-6}$ & -0.00017 & 0.002561 & -0.0242 & 0.169838 & -0.80344 & 1.891615 \\
\hline 6 & 14.38 & $-7.61 \times 10^{-8}$ & $5.73 \times 10^{-6}$ & -0.00017 & 0.002692 & -0.0255 & 0.174281 & -0.79615 & 1.810658 \\
\hline 7 & 13.62 & $-4.49 \times 10^{-8}$ & $3.22 \times 10^{-6}$ & $-8.98 \times 10^{-5}$ & 0.00127 & -0.01147 & 0.094093 & -0.54922 & 1.46773 \\
\hline 8 & 12.86 & $-5.94 \times 10^{-8}$ & $4.41 \times 10^{-6}$ & -0.00013 & 0.001983 & -0.01855 & 0.131392 & -0.64059 & 1.510883 \\
\hline 9 & 12.1 & $-4.93 \times 10^{-8}$ & $3.60 \times 10^{-6}$ & -0.0001 & 0.001547 & -0.01442 & 0.107759 & -0.56267 & 1.376621 \\
\hline 10 & 11.35 & $-3.84 \times 10^{-8}$ & $2.83 \times 10^{-6}$ & $-8.28 \times 10^{-5}$ & 0.001264 & -0.01231 & 0.097383 & -0.52466 & 1.287835 \\
\hline 11 & 10.59 & $-5.38 \times 10^{-8}$ & $4.02 \times 10^{-6}$ & -0.00012 & 0.001938 & -0.01902 & 0.133029 & -0.61068 & 1.328016 \\
\hline 12 & 9.84 & $-6.36 \times 10^{-8}$ & $4.95 \times 10^{-6}$ & -0.00016 & 0.002595 & -0.02585 & 0.170093 & -0.70143 & 1.37417 \\
\hline 13 & 9.08 & $-4.43 \times 10^{-8}$ & $3.27 \times 10^{-6}$ & $-9.63 \times 10^{-5}$ & 0.001497 & -0.01446 & 0.103187 & -0.49284 & 1.091061 \\
\hline 14 & 8.33 & $-2.86 \times 10^{-8}$ & $2.02 \times 10^{-6}$ & $-5.61 \times 10^{-5}$ & 0.000817 & -0.0079 & 0.065707 & -0.37112 & 0.906196 \\
\hline 15 & 7.57 & $-2.23 \times 10^{-8}$ & $1.15 \times 10^{-6}$ & $-1.53 \times 10^{-5}$ & $-9.89 \mathrm{E}-05$ & 0.00298 & -0.00386 & -0.14594 & 0.599584 \\
\hline 16 & 6.82 & $-7.29 \times 10^{-8}$ & $4.99 \times 10^{-6}$ & -0.00013 & 0.001829 & -0.0146 & 0.084527 & -0.36466 & 0.780318 \\
\hline 17 & 6.06 & $-8.53 \times 10^{-8}$ & $6.10 \times 10^{-6}$ & -0.00017 & 0.002612 & -0.02305 & 0.133651 & -0.49913 & 0.888727 \\
\hline 18 & 5.31 & $-1.31 \times 10^{-7}$ & $9.80 \times 10^{-6}$ & -0.0003 & 0.004725 & -0.04346 & 0.241628 & -0.77882 & 1.139603 \\
\hline 19 & 4.56 & $-2.51 \times 10^{-7}$ & $1.94 \times 10^{-5}$ & -0.00061 & 0.01013 & -0.09551 & 0.518007 & -1.50914 & 1.848456 \\
\hline 20 & 3.8 & $-2.91 \times 10^{-7}$ & $2.16 \times 10^{-5}$ & -0.00065 & 0.010106 & -0.08874 & 0.441954 & -1.16733 & 1.286324 \\
\hline 21 & 3.04 & $-4.20 \times 10^{-7}$ & $3.08 \times 10^{-5}$ & -0.0009 & 0.013482 & -0.10939 & 0.470893 & -0.95257 & 0.640136 \\
\hline 22 & 2.29 & $-1.11 \times 10^{-8}$ & $-1.13 \times 10^{-5}$ & 0.000112 & -0.00337 & 0.048202 & -0.35222 & 1.258894 & -1.70139 \\
\hline 23 & 1.54 & $-3.55 \times 10^{-7}$ & $2.67 \times 10^{-5}$ & -0.00082 & 0.013007 & -0.11706 & 0.596926 & -1.60916 & 1.813668 \\
\hline 24 & 0.79 & $-1.29 \times 10^{-7}$ & $8.34 \times 10^{-5}$ & -0.0002 & 0.002153 & -0.00725 & -0.03711 & 0.326281 & -0.60025 \\
\hline 25 & 0.11 & $2.79 \times 10^{-7}$ & $-2.34 \times 10^{-5}$ & 0.000803 & -0.0144 & 0.144452 & -0.79752 & 2.20042 & -2.32417 \\
\hline
\end{tabular}


Table A4. Polynomial coefficients for Ka-band $A_{2}$ model in dB (Equation (7)).

\begin{tabular}{|c|c|c|c|c|c|c|c|c|c|}
\hline $\begin{array}{c}\text { Beam } \\
\text { No }\end{array}$ & EIA & $a_{21}$ & $a_{22}$ & $a_{23}$ & $a_{24}$ & $a_{25}$ & $a_{26}$ & $a_{27}$ & $a_{28}$ \\
\hline 1 & 18.16 & $2.42 \times 10^{-7}$ & $-1.95 \times 10^{-5}$ & 0.000630 & -0.010285 & 0.086533 & -0.327061 & 0.300739 & 1.182616 \\
\hline 2 & 17.4 & $2.24 \times 10^{-7}$ & $-1.81 \times 10^{-5}$ & 0.000584 & -0.009520 & 0.079453 & -0.290412 & 0.197955 & 1.253774 \\
\hline 3 & 16.64 & $1.64 \times 10^{-7}$ & $-1.33 \times 10^{-5}$ & 0.000430 & -0.006907 & 0.054482 & -0.155678 & -0.187766 & 1.661966 \\
\hline 4 & 15.88 & $1.64 \times 10^{-7}$ & $-1.35 \times 10^{-5}$ & 0.000440 & -0.007202 & 0.058886 & -0.190922 & -0.049940 & 1.412138 \\
\hline 5 & 15.13 & $1.77 \times 10^{-7}$ & $-1.46 \times 10^{-5}$ & 0.000483 & -0.008099 & 0.069775 & -0.266707 & 0.221679 & 0.986715 \\
\hline 6 & 14.37 & $1.88 \times 10^{-7}$ & $-1.56 \times 10^{-5}$ & 0.000520 & -0.008830 & 0.078501 & -0.327420 & 0.441136 & 0.634368 \\
\hline 7 & 13.61 & $2.07 \times 10^{-7}$ & $-1.72 \times 10^{-5}$ & 0.000577 & -0.009927 & 0.090532 & -0.402978 & 0.686282 & 0.284689 \\
\hline 8 & 12.86 & $2.00 \times 10^{-7}$ & $-1.66 \times 10^{-5}$ & 0.000560 & -0.009654 & 0.088519 & -0.398082 & 0.695758 & 0.208310 \\
\hline 9 & 12.1 & $1.84 \times 10^{-7}$ & $-1.55 \times 10^{-5}$ & 0.000527 & -0.009213 & 0.085757 & -0.394888 & 0.730148 & 0.078091 \\
\hline 10 & 11.35 & $2.21 \times 10^{-7}$ & $-1.85 \times 10^{-5}$ & 0.000628 & -0.010983 & 0.103633 & -0.497933 & 1.038398 & -0.317011 \\
\hline 11 & 10.59 & $1.88 \times 10^{-7}$ & $-1.59 \times 10^{-5}$ & 0.000545 & -0.009590 & 0.090552 & -0.430458 & 0.863195 & -0.171659 \\
\hline 12 & 9.84 & $1.75 \times 10^{-7}$ & $-1.51 \times 10^{-5}$ & 0.000530 & -0.009536 & 0.092273 & -0.453516 & 0.966268 & -0.354499 \\
\hline 13 & 9.08 & $1.93 \times 10^{-7}$ & $-1.63 \times 10^{-5}$ & 0.000558 & -0.009872 & 0.094156 & -0.458488 & 0.974761 & -0.398545 \\
\hline 14 & 8.33 & $1.83 \times 10^{-7}$ & $-1.56 \times 10^{-5}$ & 0.000540 & -0.009598 & 0.091517 & -0.442654 & 0.922165 & -0.358762 \\
\hline 15 & 7.57 & $1.86 \times 10^{-7}$ & $-1.58 \times 10^{-5}$ & 0.000540 & -0.009504 & 0.089661 & -0.428214 & 0.873555 & -0.330738 \\
\hline 16 & 6.82 & $1.33 \times 10^{-7}$ & $-1.14 \times 10^{-5}$ & 0.000390 & -0.006815 & 0.062436 & -0.274513 & 0.433755 & 0.121128 \\
\hline 17 & 6.06 & $6.59 \times 10^{-8}$ & $-5.83 \times 10^{-6}$ & 0.000203 & -0.003484 & 0.029146 & -0.091183 & -0.069137 & 0.611545 \\
\hline 18 & 5.31 & $-5.98 \times 10^{-8}$ & $4.23 \times 10^{-6}$ & -0.000126 & 0.002153 & -0.024887 & 0.192571 & -0.805417 & 1.298094 \\
\hline 19 & 4.55 & $-1.88 \times 10^{-7}$ & $1.43 \times 10^{-5}$ & -0.000445 & 0.007450 & -0.073550 & 0.434311 & -1.379665 & 1.725746 \\
\hline 20 & 3.8 & $-2.29 \times 10^{-7}$ & $1.76 \times 10^{-5}$ & -0.000545 & 0.008844 & -0.081123 & 0.420976 & -1.104958 & 1.037734 \\
\hline 21 & 3.04 & $-5.07 \times 10^{-8}$ & $1.79 \times 10^{-6}$ & 0.000033 & -0.002468 & 0.045852 & -0.391507 & 1.617923 & -2.622437 \\
\hline 22 & 2.29 & $-3.10 \times 10^{-7}$ & $2.39 \times 10^{-5}$ & -0.000747 & 0.012150 & -0.110696 & 0.558874 & -1.391901 & 1.206958 \\
\hline 23 & 1.54 & $9.61 \times 10^{-8}$ & $-1.01 \times 10^{-5}$ & 0.000419 & -0.008970 & 0.106483 & -0.701081 & 2.392505 & -3.269356 \\
\hline 24 & 0.78 & $-2.32 \times 10^{-7}$ & $1.82 \times 10^{-5}$ & -0.000592 & 0.010423 & -0.108244 & 0.664801 & -2.196144 & 2.936393 \\
\hline 25 & 0.03 & $2.58 \times 10^{-6}$ & -0.000205 & 0.006542 & -0.107272 & 0.958791 & -4.604580 & 11.119489 & -10.804452 \\
\hline
\end{tabular}




\section{Appendix B}

Table A5. SST correction factor (W) for Ku-band model for EIA $=18^{\circ}$ in linear unit (Equation (8)). The bins with inadequate observations are shown as not-a-number $(\mathrm{NaN})$.

\begin{tabular}{|c|c|c|c|c|c|c|c|c|c|c|c|c|c|c|c|c|c|c|c|c|}
\hline \multirow{2}{*}{$\begin{array}{l}\text { SST } \\
\text { (C) }\end{array}$} & \multicolumn{20}{|c|}{ WS (m/s) } \\
\hline & 1 & 2 & 3 & 4 & 5 & 6 & 7 & 7 & 9 & 10 & 11 & 12 & 13 & 14 & 15 & 16 & 17 & 18 & 19 & 20 \\
\hline-3 & $\mathrm{NaN}$ & 1.31 & 1.15 & 1.10 & 1.07 & 1.04 & 1.02 & 1.01 & 1.00 & 0.99 & 0.98 & 0.98 & 0.98 & 1.01 & 1.01 & 1.00 & 0.98 & 0.95 & 0.93 & 0.88 \\
\hline-2 & $\mathrm{NaN}$ & 1.28 & 1.17 & 1.09 & 1.05 & 1.03 & 1.02 & 1.00 & 0.99 & 0.97 & 0.95 & 0.95 & 0.94 & 0.95 & 0.95 & 0.93 & 0.92 & 0.91 & 0.91 & 0.88 \\
\hline-1 & $\mathrm{NaN}$ & 1.20 & 1.12 & 1.06 & 1.04 & 1.02 & 1.01 & 0.99 & 0.98 & 0.96 & 0.94 & 0.93 & 0.91 & 0.91 & 0.91 & 0.89 & 0.88 & 0.88 & 0.88 & 0.86 \\
\hline 0 & 1.26 & 1.15 & 1.08 & 1.04 & 1.03 & 1.02 & 1.00 & 0.99 & 0.97 & 0.95 & 0.94 & 0.92 & 0.91 & 0.91 & 0.90 & 0.88 & 0.88 & 0.88 & 0.89 & 0.87 \\
\hline 1 & 1.25 & 1.15 & 1.07 & 1.03 & 1.02 & 1.01 & 1.00 & 0.99 & 0.97 & 0.95 & 0.94 & 0.92 & 0.92 & 0.92 & 0.91 & 0.90 & 0.89 & 0.90 & 0.91 & 0.89 \\
\hline 2 & 1.24 & 1.14 & 1.06 & 1.03 & 1.02 & 1.01 & 1.00 & 0.99 & 0.98 & 0.97 & 0.95 & 0.94 & 0.93 & 0.93 & 0.93 & 0.92 & 0.92 & 0.92 & 0.93 & 0.91 \\
\hline 3 & 1.20 & 1.12 & 1.06 & 1.03 & 1.02 & 1.02 & 1.01 & 1.00 & 0.99 & 0.98 & 0.97 & 0.95 & 0.94 & 0.94 & 0.94 & 0.94 & 0.94 & 0.94 & 0.95 & 0.93 \\
\hline 4 & 1.20 & 1.13 & 1.06 & 1.03 & 1.03 & 1.02 & 1.01 & 1.00 & 1.00 & 1.00 & 0.98 & 0.96 & 0.96 & 0.96 & 0.96 & 0.95 & 0.95 & 0.95 & 0.96 & 0.95 \\
\hline 5 & 1.21 & 1.13 & 1.06 & 1.04 & 1.03 & 1.03 & 1.02 & 1.01 & 1.01 & 1.00 & 0.99 & 0.97 & 0.97 & 0.97 & 0.97 & 0.97 & 0.96 & 0.96 & 0.95 & 0.94 \\
\hline 6 & 1.18 & 1.14 & 1.07 & 1.04 & 1.03 & 1.03 & 1.02 & 1.01 & 1.01 & 1.00 & 0.99 & 0.98 & 0.98 & 0.98 & 0.98 & 0.98 & 0.98 & 0.97 & 0.96 & 0.94 \\
\hline 7 & 1.13 & 1.14 & 1.07 & 1.03 & 1.02 & 1.02 & 1.01 & 1.01 & 1.01 & 1.01 & 1.00 & 0.99 & 0.99 & 0.99 & 0.99 & 0.99 & 0.99 & 0.98 & 0.98 & 0.96 \\
\hline 8 & 1.11 & 1.12 & 1.06 & 1.03 & 1.02 & 1.01 & 1.01 & 1.01 & 1.01 & 1.01 & 1.00 & 0.99 & 0.99 & 1.00 & 0.99 & 0.99 & 0.99 & 0.98 & 0.99 & 0.98 \\
\hline 9 & 1.06 & 1.10 & 1.06 & 1.03 & 1.02 & 1.01 & 1.01 & 1.01 & 1.01 & 1.01 & 1.01 & 1.00 & 0.99 & 1.00 & 1.00 & 0.99 & 0.99 & 0.99 & 1.00 & 0.99 \\
\hline 10 & 1.04 & 1.07 & 1.05 & 1.02 & 1.01 & 1.01 & 1.01 & 1.01 & 1.02 & 1.01 & 1.01 & 1.00 & 1.00 & 1.00 & 1.00 & 1.00 & 0.99 & 0.99 & 1.00 & 0.98 \\
\hline 11 & 1.02 & 1.05 & 1.03 & 1.01 & 1.01 & 1.01 & 1.01 & 1.01 & 1.02 & 1.01 & 1.01 & 1.00 & 1.00 & 1.01 & 1.01 & 1.00 & 0.99 & 0.98 & 0.98 & 0.97 \\
\hline 12 & 1.03 & 1.05 & 1.03 & 1.02 & 1.01 & 1.01 & 1.01 & 1.01 & 1.02 & 1.02 & 1.01 & 1.01 & 1.01 & 1.01 & 1.01 & 1.00 & 0.99 & 0.98 & 0.98 & 0.97 \\
\hline 13 & 1.07 & 1.05 & 1.03 & 1.02 & 1.01 & 1.01 & 1.01 & 1.01 & 1.01 & 1.02 & 1.01 & 1.01 & 1.01 & 1.01 & 1.01 & 1.01 & 1.01 & 1.00 & 1.00 & 0.98 \\
\hline 14 & 1.05 & 1.03 & 1.01 & 1.01 & 1.01 & 1.01 & 1.01 & 1.01 & 1.01 & 1.01 & 1.01 & 1.00 & 1.00 & 1.01 & 1.01 & 1.02 & 1.01 & 1.00 & 1.00 & 0.99 \\
\hline 15 & 1.00 & 1.00 & 1.00 & 1.00 & 1.00 & 1.00 & 1.00 & 1.00 & 1.00 & 1.00 & 1.00 & 1.00 & 1.00 & 1.00 & 1.00 & 1.00 & 1.00 & 1.00 & 1.00 & 1.00 \\
\hline 16 & 1.01 & 0.98 & 0.98 & 0.98 & 0.99 & 0.99 & 0.99 & 0.99 & 0.99 & 0.99 & 0.99 & 0.99 & 0.99 & 1.00 & 1.00 & 1.00 & 1.00 & 1.00 & 1.01 & 1.00 \\
\hline 17 & 1.03 & 0.96 & 0.97 & 0.97 & 0.98 & 0.99 & 0.99 & 0.99 & 0.99 & 0.99 & 0.99 & 0.98 & 0.99 & 1.01 & 1.01 & 1.00 & 1.00 & 0.99 & 0.99 & 0.98 \\
\hline 18 & 1.00 & 0.95 & 0.95 & 0.96 & 0.97 & 0.98 & 0.98 & 0.98 & 0.98 & 0.98 & 0.98 & 0.98 & 0.99 & 1.00 & 1.01 & 0.99 & 1.01 & 1.01 & 1.00 & 0.98 \\
\hline 19 & 0.98 & 0.94 & 0.94 & 0.96 & 0.97 & 0.98 & 0.98 & 0.98 & 0.98 & 0.98 & 0.98 & 0.98 & 0.98 & 1.00 & 1.00 & 1.01 & 1.03 & 1.02 & 1.01 & 0.99 \\
\hline 20 & 0.95 & 0.91 & 0.94 & 0.96 & 0.97 & 0.98 & 0.98 & 0.98 & 0.98 & 0.98 & 0.98 & 0.99 & 0.99 & 1.00 & 1.01 & 1.03 & 1.03 & 1.02 & 1.00 & 0.93 \\
\hline 21 & 0.91 & 0.90 & 0.93 & 0.96 & 0.97 & 0.98 & 0.98 & 0.98 & 0.99 & 0.99 & 0.99 & 0.99 & 1.00 & 1.01 & 1.01 & 1.03 & 1.02 & 1.02 & 1.01 & 0.93 \\
\hline 22 & 0.88 & 0.90 & 0.94 & 0.96 & 0.97 & 0.98 & 0.99 & 0.99 & 0.99 & 1.00 & 0.99 & 0.99 & 0.99 & 1.00 & 1.01 & 1.00 & 1.00 & 1.02 & 1.02 & 0.97 \\
\hline 23 & 0.87 & 0.89 & 0.93 & 0.96 & 0.98 & 0.99 & 0.99 & 1.00 & 1.00 & 1.01 & 1.00 & 1.00 & 0.99 & 0.99 & 1.00 & 0.98 & 0.97 & 0.98 & 1.00 & 0.99 \\
\hline 24 & 0.83 & 0.87 & 0.93 & 0.97 & 0.98 & 0.99 & 1.00 & 1.00 & 1.01 & 1.02 & 1.02 & 1.01 & 1.01 & 1.00 & 1.00 & 0.97 & 0.93 & 0.96 & 1.02 & 1.08 \\
\hline 25 & 0.81 & 0.87 & 0.94 & 0.98 & 0.99 & 1.00 & 1.01 & 1.02 & 1.02 & 1.04 & 1.03 & 1.03 & 1.02 & 1.01 & 1.01 & 1.00 & 0.97 & 1.00 & 1.06 & 1.09 \\
\hline 26 & 0.84 & 0.90 & 0.95 & 0.99 & 1.01 & 1.01 & 1.02 & 1.03 & 1.03 & 1.05 & 1.05 & 1.04 & 1.03 & 1.03 & 1.03 & 1.03 & 1.04 & 1.04 & 1.00 & 0.90 \\
\hline 27 & 0.86 & 0.92 & 0.98 & 1.01 & 1.01 & 1.02 & 1.03 & 1.03 & 1.04 & 1.05 & 1.05 & 1.05 & 1.05 & 1.05 & 1.02 & 1.02 & 1.03 & 1.00 & 0.98 & 0.87 \\
\hline 28 & 0.89 & 0.96 & 1.01 & 1.01 & 1.02 & 1.03 & 1.03 & 1.03 & 1.04 & 1.04 & 1.05 & 1.05 & 1.07 & 1.05 & 1.02 & 1.01 & 1.05 & 1.05 & 1.22 & $\mathrm{NaN}$ \\
\hline 29 & 0.90 & 0.97 & 1.00 & 1.00 & 1.01 & 1.02 & 1.03 & 1.03 & 1.03 & 1.03 & 1.04 & 1.05 & 1.06 & 1.06 & 1.04 & 1.03 & 1.01 & 1.27 & $\mathrm{NaN}$ & $\mathrm{NaN}$ \\
\hline 30 & 0.87 & 0.94 & 0.97 & 0.98 & 1.00 & 1.01 & 1.02 & 1.02 & 1.02 & 1.02 & 1.02 & 1.04 & 1.03 & 1.03 & 1.04 & 1.04 & 0.95 & $\mathrm{NaN}$ & $\mathrm{NaN}$ & $\mathrm{NaN}$ \\
\hline 31 & 0.81 & 0.88 & 0.92 & 0.95 & 0.98 & 1.00 & 1.00 & 1.00 & 0.99 & 0.99 & 0.98 & 0.98 & 0.97 & 0.92 & 0.94 & 0.90 & 0.79 & $\mathrm{NaN}$ & $\mathrm{NaN}$ & $\mathrm{NaN}$ \\
\hline 32 & 0.66 & 0.75 & 0.82 & 0.89 & 0.94 & 0.96 & 0.95 & 0.95 & 0.94 & 0.95 & 0.93 & 0.94 & 0.92 & 0.85 & 0.88 & $\mathrm{NaN}$ & $\mathrm{NaN}$ & $\mathrm{NaN}$ & $\mathrm{NaN}$ & $\mathrm{NaN}$ \\
\hline 33 & 0.50 & 0.69 & 0.82 & 0.85 & 0.91 & 0.94 & 0.92 & 0.88 & 0.88 & 0.91 & 0.87 & 0.94 & 0.83 & $\mathrm{NaN}$ & $\mathrm{NaN}$ & $\mathrm{NaN}$ & $\mathrm{NaN}$ & $\mathrm{NaN}$ & $\mathrm{NaN}$ & $\mathrm{NaN}$ \\
\hline 34 & 0.42 & 0.96 & 0.93 & 0.87 & 0.94 & 0.90 & 0.89 & 0.89 & 0.92 & 0.88 & 0.82 & 0.99 & $\mathrm{NaN}$ & $\mathrm{NaN}$ & $\mathrm{NaN}$ & $\mathrm{NaN}$ & $\mathrm{NaN}$ & $\mathrm{NaN}$ & $\mathrm{NaN}$ & $\mathrm{NaN}$ \\
\hline
\end{tabular}


Table A6. SST correction factor $(\mathrm{W})$ for Ka-band model for EIA $=18^{\circ}$ in linear unit (Equation (8)). The bins with inadequate observations are shown as not-a-number $(\mathrm{NaN})$.

\begin{tabular}{|c|c|c|c|c|c|c|c|c|c|c|c|c|c|c|c|c|c|c|c|c|}
\hline \multirow{2}{*}{$\begin{array}{l}\text { SST } \\
\text { (C) }\end{array}$} & \multicolumn{20}{|c|}{ WS (m/s) } \\
\hline & 1 & 2 & 3 & 4 & 5 & 6 & 7 & 7 & 9 & 10 & 11 & 12 & 13 & 14 & 15 & 16 & 17 & 18 & 19 & 20 \\
\hline-3 & $\mathrm{NaN}$ & 1.25 & 1.08 & 1.03 & 0.99 & 0.95 & 0.92 & 0.89 & 0.88 & 0.88 & 0.89 & 0.90 & 0.90 & 0.92 & 0.92 & 0.92 & 0.90 & 0.88 & 0.86 & 0.82 \\
\hline-2 & $\mathrm{NaN}$ & 1.22 & 1.11 & 1.02 & 0.97 & 0.94 & 0.92 & 0.90 & 0.88 & 0.87 & 0.86 & 0.86 & 0.86 & 0.87 & 0.87 & 0.86 & 0.85 & 0.84 & 0.84 & 0.82 \\
\hline-1 & $\mathrm{NaN}$ & 1.13 & 1.06 & 0.99 & 0.96 & 0.94 & 0.92 & 0.90 & 0.88 & 0.86 & 0.85 & 0.84 & 0.84 & 0.84 & 0.84 & 0.83 & 0.82 & 0.81 & 0.81 & 0.81 \\
\hline 0 & 1.28 & 1.10 & 1.02 & 0.98 & 0.96 & 0.95 & 0.92 & 0.90 & 0.88 & 0.87 & 0.85 & 0.84 & 0.84 & 0.84 & 0.84 & 0.83 & 0.82 & 0.82 & 0.83 & 0.81 \\
\hline 1 & 1.28 & 1.11 & 1.02 & 0.98 & 0.96 & 0.95 & 0.93 & 0.91 & 0.89 & 0.88 & 0.86 & 0.85 & 0.85 & 0.85 & 0.85 & 0.84 & 0.84 & 0.85 & 0.85 & 0.83 \\
\hline 2 & 1.28 & 1.10 & 1.02 & 0.98 & 0.96 & 0.95 & 0.94 & 0.92 & 0.91 & 0.90 & 0.88 & 0.87 & 0.86 & 0.87 & 0.87 & 0.86 & 0.86 & 0.87 & 0.87 & 0.85 \\
\hline 3 & 1.24 & 1.09 & 1.02 & 0.98 & 0.97 & 0.97 & 0.95 & 0.94 & 0.93 & 0.92 & 0.90 & 0.89 & 0.88 & 0.89 & 0.89 & 0.89 & 0.89 & 0.89 & 0.90 & 0.88 \\
\hline 4 & 1.25 & 1.11 & 1.03 & 0.99 & 0.98 & 0.98 & 0.96 & 0.95 & 0.94 & 0.94 & 0.92 & 0.91 & 0.90 & 0.91 & 0.91 & 0.91 & 0.91 & 0.91 & 0.91 & 0.90 \\
\hline 5 & 1.27 & 1.11 & 1.04 & 1.00 & 0.99 & 0.98 & 0.97 & 0.96 & 0.95 & 0.95 & 0.93 & 0.92 & 0.92 & 0.92 & 0.93 & 0.93 & 0.92 & 0.91 & 0.90 & 0.89 \\
\hline 6 & 1.23 & 1.12 & 1.05 & 1.01 & 0.99 & 0.99 & 0.97 & 0.96 & 0.96 & 0.96 & 0.95 & 0.94 & 0.94 & 0.94 & 0.94 & 0.94 & 0.94 & 0.93 & 0.91 & 0.89 \\
\hline 7 & 1.18 & 1.13 & 1.04 & 1.00 & 0.99 & 0.99 & 0.97 & 0.97 & 0.97 & 0.96 & 0.95 & 0.95 & 0.95 & 0.95 & 0.95 & 0.95 & 0.95 & 0.94 & 0.93 & 0.91 \\
\hline 8 & 1.15 & 1.12 & 1.04 & 1.00 & 0.99 & 0.99 & 0.98 & 0.98 & 0.98 & 0.97 & 0.97 & 0.96 & 0.95 & 0.96 & 0.96 & 0.96 & 0.96 & 0.94 & 0.94 & 0.93 \\
\hline 9 & 1.09 & 1.09 & 1.04 & 1.01 & 0.99 & 0.99 & 0.98 & 0.98 & 0.99 & 0.98 & 0.98 & 0.96 & 0.96 & 0.96 & 0.97 & 0.97 & 0.96 & 0.96 & 0.96 & 0.94 \\
\hline 10 & 1.06 & 1.06 & 1.03 & 1.00 & 0.99 & 0.99 & 0.99 & 0.99 & 1.00 & 0.99 & 0.98 & 0.97 & 0.97 & 0.97 & 0.98 & 0.98 & 0.97 & 0.96 & 0.97 & 0.94 \\
\hline 11 & 1.05 & 1.05 & 1.03 & 1.00 & 0.99 & 0.99 & 0.99 & 1.00 & 1.00 & 1.00 & 0.99 & 0.98 & 0.98 & 0.99 & 0.99 & 0.98 & 0.97 & 0.96 & 0.95 & 0.94 \\
\hline 12 & 1.08 & 1.05 & 1.03 & 1.01 & 1.00 & 1.00 & 1.00 & 1.00 & 1.00 & 1.00 & 1.00 & 0.99 & 0.99 & 1.00 & 1.00 & 0.99 & 0.98 & 0.96 & 0.95 & 0.95 \\
\hline 13 & 1.11 & 1.04 & 1.02 & 1.01 & 1.01 & 1.01 & 1.00 & 1.00 & 1.01 & 1.01 & 1.00 & 1.00 & 1.00 & 1.00 & 1.00 & 1.00 & 1.00 & 0.99 & 0.98 & 0.96 \\
\hline 14 & 1.06 & 1.02 & 1.01 & 1.01 & 1.01 & 1.01 & 1.01 & 1.00 & 1.00 & 1.01 & 1.00 & 1.00 & 1.00 & 1.00 & 1.01 & 1.01 & 1.01 & 1.00 & 0.99 & 0.98 \\
\hline 15 & 1.00 & 1.00 & 1.00 & 1.00 & 1.00 & 1.00 & 1.00 & 1.00 & 1.00 & 1.00 & 1.00 & 1.00 & 1.00 & 1.00 & 1.00 & 1.00 & 1.00 & 1.00 & 1.00 & 1.00 \\
\hline 16 & 1.03 & 0.98 & 0.99 & 0.99 & 1.00 & 1.00 & 1.00 & 1.00 & 1.00 & 1.00 & 1.00 & 0.99 & 1.00 & 1.01 & 1.01 & 1.01 & 1.01 & 1.01 & 1.01 & 1.01 \\
\hline 17 & 1.05 & 0.96 & 0.97 & 0.98 & 0.99 & 1.00 & 0.99 & 0.99 & 0.99 & 1.00 & 0.99 & 0.99 & 1.00 & 1.02 & 1.02 & 1.02 & 1.02 & 1.01 & 1.00 & 0.99 \\
\hline 18 & 1.04 & 0.95 & 0.95 & 0.97 & 0.98 & 0.99 & 0.99 & 0.99 & 0.99 & 0.99 & 1.00 & 0.99 & 1.00 & 1.02 & 1.02 & 1.02 & 1.04 & 1.04 & 1.01 & 0.98 \\
\hline 19 & 1.01 & 0.93 & 0.95 & 0.97 & 0.98 & 0.99 & 0.99 & 0.99 & 0.99 & 1.00 & 1.00 & 1.00 & 1.00 & 1.01 & 1.02 & 1.04 & 1.07 & 1.06 & 1.02 & 0.99 \\
\hline 20 & 0.97 & 0.91 & 0.95 & 0.97 & 0.98 & 1.00 & 1.00 & 1.00 & 1.00 & 1.01 & 1.01 & 1.01 & 1.01 & 1.03 & 1.04 & 1.06 & 1.07 & 1.05 & 1.02 & 0.95 \\
\hline 21 & 0.92 & 0.90 & 0.95 & 0.98 & 0.99 & 1.00 & 1.00 & 1.01 & 1.02 & 1.02 & 1.01 & 1.02 & 1.03 & 1.04 & 1.05 & 1.07 & 1.07 & 1.06 & 1.03 & 0.95 \\
\hline 22 & 0.89 & 0.90 & 0.96 & 0.98 & 1.00 & 1.01 & 1.02 & 1.03 & 1.04 & 1.04 & 1.03 & 1.02 & 1.02 & 1.04 & 1.06 & 1.05 & 1.04 & 1.04 & 1.03 & 0.99 \\
\hline 23 & 0.88 & 0.89 & 0.96 & 0.99 & 1.01 & 1.03 & 1.03 & 1.04 & 1.06 & 1.06 & 1.05 & 1.04 & 1.03 & 1.03 & 1.05 & 1.04 & 1.01 & 1.00 & 1.02 & 1.02 \\
\hline 24 & 0.83 & 0.87 & 0.96 & 1.01 & 1.02 & 1.04 & 1.05 & 1.07 & 1.08 & 1.08 & 1.07 & 1.06 & 1.06 & 1.04 & 1.04 & 1.03 & 0.99 & 1.02 & 1.07 & 1.16 \\
\hline 25 & 0.82 & 0.88 & 0.97 & 1.02 & 1.04 & 1.06 & 1.08 & 1.09 & 1.10 & 1.11 & 1.10 & 1.08 & 1.08 & 1.06 & 1.07 & 1.05 & 1.02 & 1.08 & 1.16 & 1.21 \\
\hline 26 & 0.84 & 0.91 & 0.99 & 1.04 & 1.06 & 1.08 & 1.09 & 1.11 & 1.12 & 1.13 & 1.12 & 1.10 & 1.09 & 1.08 & 1.08 & 1.09 & 1.14 & 1.16 & 1.13 & 0.99 \\
\hline 27 & 0.88 & 0.94 & 1.03 & 1.06 & 1.07 & 1.09 & 1.11 & 1.12 & 1.13 & 1.13 & 1.12 & 1.12 & 1.11 & 1.11 & 1.08 & 1.10 & 1.15 & 1.12 & 1.10 & 0.95 \\
\hline 28 & 0.93 & 0.99 & 1.06 & 1.07 & 1.08 & 1.10 & 1.11 & 1.12 & 1.13 & 1.12 & 1.12 & 1.12 & 1.13 & 1.10 & 1.07 & 1.08 & 1.15 & 1.20 & 1.40 & 1.16 \\
\hline 29 & 0.92 & 1.00 & 1.05 & 1.06 & 1.07 & 1.09 & 1.11 & 1.12 & 1.12 & 1.11 & 1.11 & 1.12 & 1.12 & 1.11 & 1.11 & 1.09 & 1.06 & 1.39 & $\mathrm{NaN}$ & $\mathrm{NaN}$ \\
\hline 30 & 0.89 & 0.97 & 1.02 & 1.03 & 1.06 & 1.09 & 1.10 & 1.10 & 1.10 & 1.09 & 1.08 & 1.10 & 1.09 & 1.10 & 1.13 & 1.11 & 0.99 & $\mathrm{NaN}$ & $\mathrm{NaN}$ & $\mathrm{NaN}$ \\
\hline 31 & 0.82 & 0.90 & 0.96 & 1.00 & 1.04 & 1.07 & 1.07 & 1.07 & 1.05 & 1.04 & 1.04 & 1.04 & 1.04 & 0.99 & 1.01 & 0.94 & 0.82 & $\mathrm{NaN}$ & $\mathrm{NaN}$ & $\mathrm{NaN}$ \\
\hline 32 & 0.66 & 0.76 & 0.86 & 0.93 & 0.99 & 1.01 & 1.01 & 1.01 & 0.99 & 1.00 & 0.98 & 1.02 & 0.96 & 0.90 & 0.89 & $\mathrm{NaN}$ & $\mathrm{NaN}$ & $\mathrm{NaN}$ & $\mathrm{NaN}$ & $\mathrm{NaN}$ \\
\hline 33 & 0.48 & 0.70 & 0.87 & 0.89 & 0.97 & 1.01 & 0.97 & 0.93 & 0.93 & 0.98 & 0.93 & 1.01 & 0.86 & $\mathrm{NaN}$ & $\mathrm{NaN}$ & $\mathrm{NaN}$ & $\mathrm{NaN}$ & $\mathrm{NaN}$ & $\mathrm{NaN}$ & $\mathrm{NaN}$ \\
\hline 34 & 0.42 & 0.97 & 0.99 & 0.92 & 1.01 & 0.98 & 0.98 & 0.96 & 0.98 & 0.95 & 0.88 & 0.97 & $\mathrm{NaN}$ & $\mathrm{NaN}$ & $\mathrm{NaN}$ & $\mathrm{NaN}$ & $\mathrm{NaN}$ & $\mathrm{NaN}$ & $\mathrm{NaN}$ & $\mathrm{NaN}$ \\
\hline
\end{tabular}




\section{References}

1. Majurec, N.; Johnson, J.T.; Tanelli, S.; Durden, S.L. Comparison of Model Predictions with Measurements of Ku-and Ka-Band near-Nadir Normalized Radar Cross Sections of the Sea Surface from the Genesis and Rapid Intensification Processes Experiment. IEEE Trans. Geosci. Remote Sens. 2014, 52, 5320-5332. [CrossRef]

2. Kummerow, C.; Barnes, W.; Kozu, T.; Shiue, J.; Simpson, J. The Tropical Rainfall Measuring Mission (TRMM) Sensor Package. J. Atmos. Ocean. Technol. 1998, 15, 809-817. [CrossRef]

3. Hou, A.Y.; Kakar, R.K.; Neeck, S.; Azarbarzin, A.A.; Kummerow, C.D.; Kojima, M.; Oki, R.; Nakamura, K.; Iguchi, T. The Global Precipitation Measurement Mission. Bull. Am. Meteorol. Soc. 2014, 95, 701-722. [CrossRef]

4. Gao, J.; Tang, G.; Hong, Y. Similarities and Improvements of GPM Dual-Frequency Precipitation Radar (DPR) upon TRMM Precipitation Radar (PR) in Global Precipitation Rate Estimation, Type Classification and Vertical Profiling. Remote Sens. 2017, 9, 1142. [CrossRef]

5. Freilich, M.H.; Vanhoff, B.A. The Relationship between Winds, Surface Roughness, and Radar Backscatter at Low Incidence Angles from TRMM Precipitation Radar Measurements. J. Atmos. Ocean. Technol. 2003, 20, 549-562. [CrossRef]

6. Jones, W.L.; Soisuvarn, S.; Park, J.; Adams, I.; Kasparis, T. Combined Active and Passive Microwave Sensing of Ocean Surface Wind Vector from TRMM. Ocean. '02 MTS/IEEE 2002, 4, 1981-1986. [CrossRef]

7. Soisuvarn, S.; Jones, W.L.; Kasparis, T. Combined Active and Passive Microwave Sensing of Ocean Surface Wind Vector from TRMM. Int. Geosci. Remote Sens. Symp. 2003, 2, 1257-1260. [CrossRef]

8. Li, L.; Im, E.; Connor, L.N.; Chang, P.S. Retrieving Ocean Surface Wind Speed from the TRMM Precipitation Radar Measurements. IEEE Trans. Geosci. Remote Sens. 2004, 42, 1271-1282. [CrossRef]

9. Tran, N.; Chapron, B. Combined Wind Vector and Sea State Impact on Ocean Nadir-Viewing Ku- And C-Band Radar CrossSections. Sensors 2006, 6, 193-207. [CrossRef]

10. Tran, N.; Chapron, B.; Vandemark, D. Effect of Long Waves on Ku-Band Ocean Radar Backscatter at Low Incidence Angles Using TRMM and Altimeter Data. IEEE Geosci. Remote Sens. Lett. 2007, 4, 542-546. [CrossRef]

11. Chu, X.; He, Y.; Karaev, V.Y. Relationships between Ku-Band Radar Backscatter and Integrated Wind and Wave Parameters at Low Incidence Angles. IEEE Trans. Geosci. Remote Sens. 2012, 50, 4599-4609. [CrossRef]

12. Chu, X.; He, Y.; Chen, G. Asymmetry and Anisotropy of Microwave Backscatter at Low Incidence Angles. IEEE Trans. Geosci. Remote Sens. 2012, 50, 4014-4024. [CrossRef]

13. Tanelli, S.; Durden, S.L.; Im, E. Simultaneous Measurements of Ku- and Ka-Band Sea Surface Cross Sections by an Airborne Radar. IEEE Geosci. Remote Sens. Lett. 2006, 3, 359-363. [CrossRef]

14. Skofronick-Jackson, G.; Petersen, W.A.; Berg, W.; Kidd, C.; Stocker, E.F.; Kirschbaum, D.B.; Kakar, R.; Braun, S.A.; Huffman, G.J.; Iguchi, T.; et al. The Global Precipitation Measurement (GPM) Mission for Science and Society. Bull. Am. Meteorol. Soc. 2017, 98, 1679-1695. [CrossRef]

15. Yan, Q.; Zhang, J.; Fan, C.; Meng, J. Analysis of Ku- and Ka-Band Sea Surface Backscattering Characteristics at Low-Incidence Angles Based on the GPM Dual-Frequency Precipitation Radar Measurements. Remote Sens. 2019, 11, 754. [CrossRef]

16. Nouguier, F.; Mouche, A.; Rascle, N.; Chapron, B.; Vandemark, D. Analysis of Dual-Frequency Ocean Backscatter Measurements at Ku-and Ka-Bands Using Near-Nadir Incidence GPM Radar Data. IEEE Geosci. Remote Sens. Lett. 2016, 13, 1310-1314. [CrossRef]

17. Iguchi, T. Dual-Frequency Precipitation Radar (DPR) on the Global Precipitation Measurement (GPM) Mission's Core Observatory. In Satellite Precipitation Measurement; Levizzani, V., Kidd, C., Kirschbaum, D.B., Kummerow, C.D., Nakamura, K., Turk, F.J., Eds.; Springer International Publishing: Cham, Switzerland, 2020; Volume 1, pp. 183-192. [CrossRef]

18. Wang, Z.; Stoffelen, A.; Fois, F.; Verhoef, A.; Zhao, C.; Lin, M.; Chen, G. SST Dependence of Ku-and C-Band Backscatter Measurements. IEEE J. Sel. Top. Appl. Earth Obs. Remote Sens. 2017, 10, 2135-2146. [CrossRef]

19. Systems, R.S.; Rosa, S.; Corporation, T.A.; Angeles, L.; Systems, S.; County, B.; City, S.L. The Status of the Tropical Rainfall Measuring Mission (TRMM) after Two Years in Orbit. J. Appl. Meteorol. 2000, 39, 1965-1982.

20. Wentz, F.J.; Draper, D. On-Orbit Absolute Calibration of the Global Precipitation Measurement Microwave Imager. J. Atmos. Ocean. Technol. 2016, 33, 1393-1412. [CrossRef]

21. Wentz, F.J.; Meissner, T.; Scott, J.; Hilburn, K.A. Remote Sensing Systems GPM GMI Daily Environmental Suite on 0.25 Deg Grid, Version 8.2, [2019]. Remote Sensing Systems, Santa Rosa, CA, USA. Available online: www.remss.com/missions/gmi (accessed on 15 January 2021).

22. Hersbach, H.; Bell, B.; Berrisford, P.; Hirahara, S.; Horányi, A.; Muñoz-Sabater, J.; Nicolas, J.; Peubey, C.; Radu, R.; Schepers, D.; et al. The ERA5 Global Reanalysis. Q. J. R. Meteorol. Soc. 2020, 146, 1999-2049. [CrossRef]

23. Tran, N.; Vandemark, D.; Ruf, C.S.; Chapron, B. The Dependence of Nadir Ocean Surface Emissivity on Wind Vector as Measured with Microwave Radiometer. IEEE Trans. Geosci. Remote Sens. 2002, 40, 515-523. [CrossRef]

24. Vandemark, D.; Chapron, B.; Feng, H.; Mouche, A. Sea Surface Reflectivity Variation with Ocean Temperature at Ka-Band Observed Using Near-Nadir Satellite Radar Data. IEEE Geosci. Remote Sens. Lett. 2016, 13, 510-514. [CrossRef]

25. Schroeder, L.C.; Boggs, D.H.; Dome, G.; Halberstam, I.M.; Jones, W.L.; Pierson, W.J.; Wentz, F.J. The Relationship between Wind Vector and Normalized Radar Cross Section Used to Derive SEASAT-A Satellite Scatterometer Winds. J. Geophys. Res. 1982, 87, 3318. [CrossRef]

26. Yueh, S.H.; Kwok, R.; Nghiem, S.V. Polarimetric Scattering and Emission Properties of Targets with Reflection Symmetry. Radio Sci. 1994, 29, 1409-1420. [CrossRef] 
27. Mouche, A.; Kudryavstev, V.; Hauser, D.; Caudal, G.; Chapron, B. Use of Dual Polarization Radar Measurements to Understand the Azimuth Behavior of the Sea Surface Baekscattered Signal. Int. Geosci. Remote Sens. Symp. 2006, 1867-1870. [CrossRef]

28. Lin, W.; Portabella, M.; Stoffelen, A.; Verhoef, A.; Wang, Z. Validation of the NSCAT-5 Geophysical Model Function for Scatsat-1 Wind Scatterometer. In Proceedings of the IGARSS 2018-2018 IEEE International Geoscience and Remote Sensing Symposium, Valencia, Spain, 22-27 July 2018; pp. 3196-3199.

29. Hossan, A.; Jacob, M.; Jones, L. Ocean Vector Wind Retrievals from TRMM Using a Novel Combined Active/Passive Algorithm. IEEE J. Sel. Top. Appl. Earth Obs. Remote Sens. 2020, 13, 5569-5579. [CrossRef]

30. Elfouhaily, T.; Vandemark, D.; Gourrion, J.; Chapron, B. Estimation of Wind Stress Using Dual-Frequency TOPEX Data. J. Geophys. Res. Ocean. 1998, 103, 25101-25108. [CrossRef] 